\title{
A stereoselective Entry into Functionalized 1,2-Diamines by Zinc-Mediated Homologation of $\alpha$-Aminoacids
}

Cam Thuy Hoang, Valérie Alezra, Regis Guillot ${ }^{\dagger}$, Cyrille Kouklovsky*

Laboratoire de Chimie des Procédés et Substances Naturelles, Institut de Chimie Moléculaire et des Matériaux d'Orsay, (UMR n'8182 - Bâtiment 410, Université Paris-Sud

F-91405 Orsay Cedex, France

cykouklo@icmo.u-psud.fr

1H, 13C NMR of compound 2a

$1 \mathrm{H}, 13 \mathrm{C}$ NMR of compound $2 \mathrm{~b}$

1H, 13C NMR of compound 2c

1H, 13C NMR of compound 2d

1H, 13C NMR of compound 3a

1H, 13C NMR of compound 3b

1H, 13C NMR of compound 3c

1H, 13C NMR of compound 3d

1H, 13C NMR of compound 5a

$1 \mathrm{H}, 13 \mathrm{C}$ NMR of compound $5 \mathrm{~b}$

$1 \mathrm{H}, 13 \mathrm{C}$ NMR of compound $5 \mathrm{c}$

1H, 13C NMR of compound 5d

1H, 13C NMR of compound 5e

1H, 13C NMR of compound $6 \mathrm{~b}$

1H, 13C NMR of compound $6 \mathrm{c}$ cis isomer

1H, 13C NMR of compound 6c trans isomer

3
4

5

6

1H, 13C NMR of compound 6d cis isomer

1H, 13C NMR of compound 6d trans isomer___ 19

1H, 13C NMR of compound 8a_

1H, 13C NMR of compound 9a_ 21

$\begin{array}{ll}1 \mathrm{H}, 13 \mathrm{C} \text { NMR of compound } 8 \mathrm{~b} & 22\end{array}$

1H, 13C NMR of compound 9b_

$\begin{array}{ll}1 \mathrm{H}, 13 \mathrm{C} \text { NMR of compound 8c } & 24\end{array}$

1H, 13C NMR of compound 9c_ 25

1H, 13C NMR of compound 8d

$\begin{array}{ll}1 H, 13 C & \text { NMR of compound 9d }\end{array}$

1H, 13C NMR of compound 8e__ 28

1H, 13C NMR of compound from saponification of $6 \mathrm{~b} \_29$

1H, 13C NMR of compound 7b _ 30

1H, 13C NMR of compound 11b_ 31

$1 \mathrm{H}, 13 \mathrm{C}$ NMR of compound $10 \mathrm{~b}$ 
Compound 2a
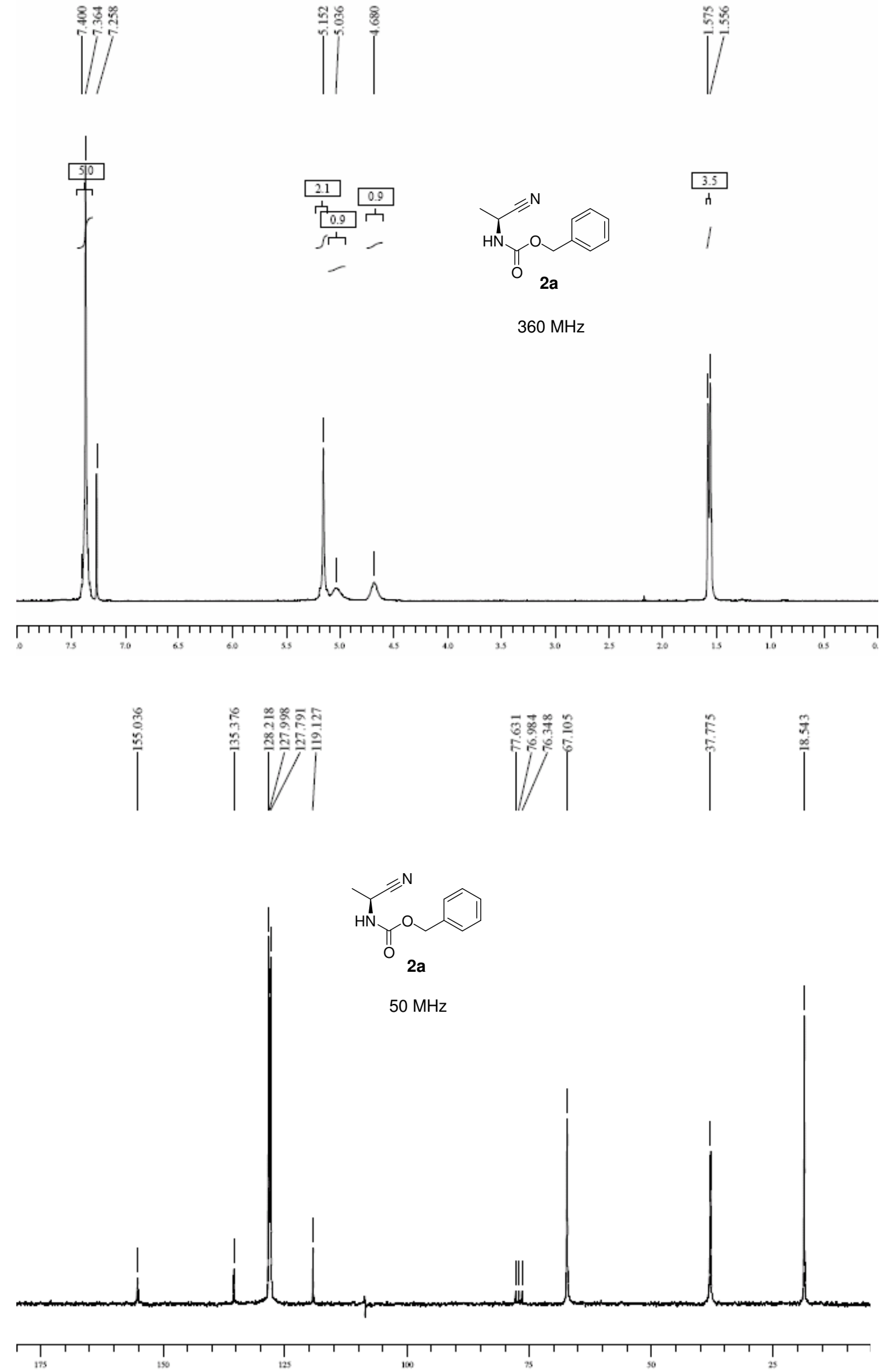
Compound 2b
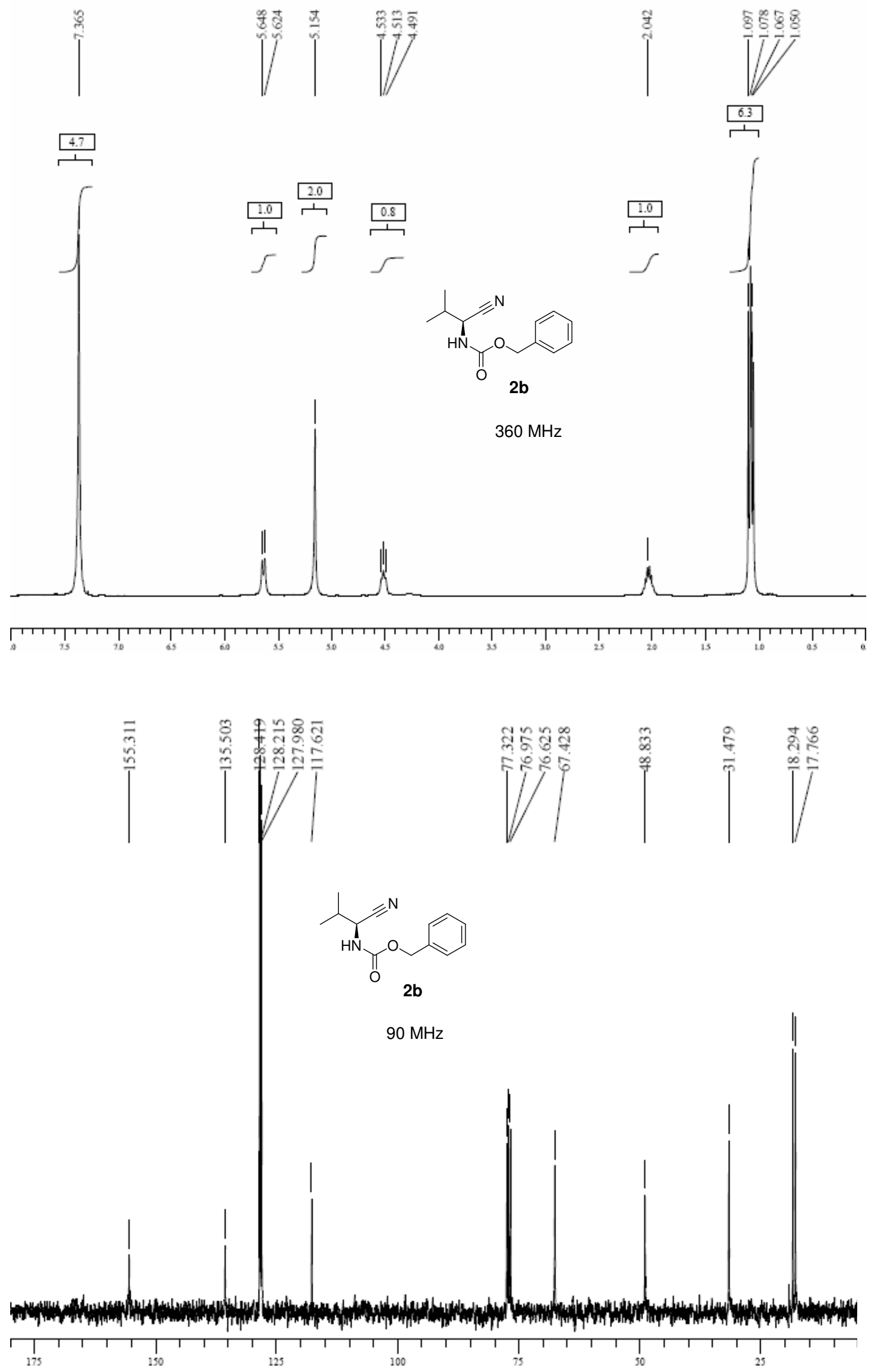
Compound 2c

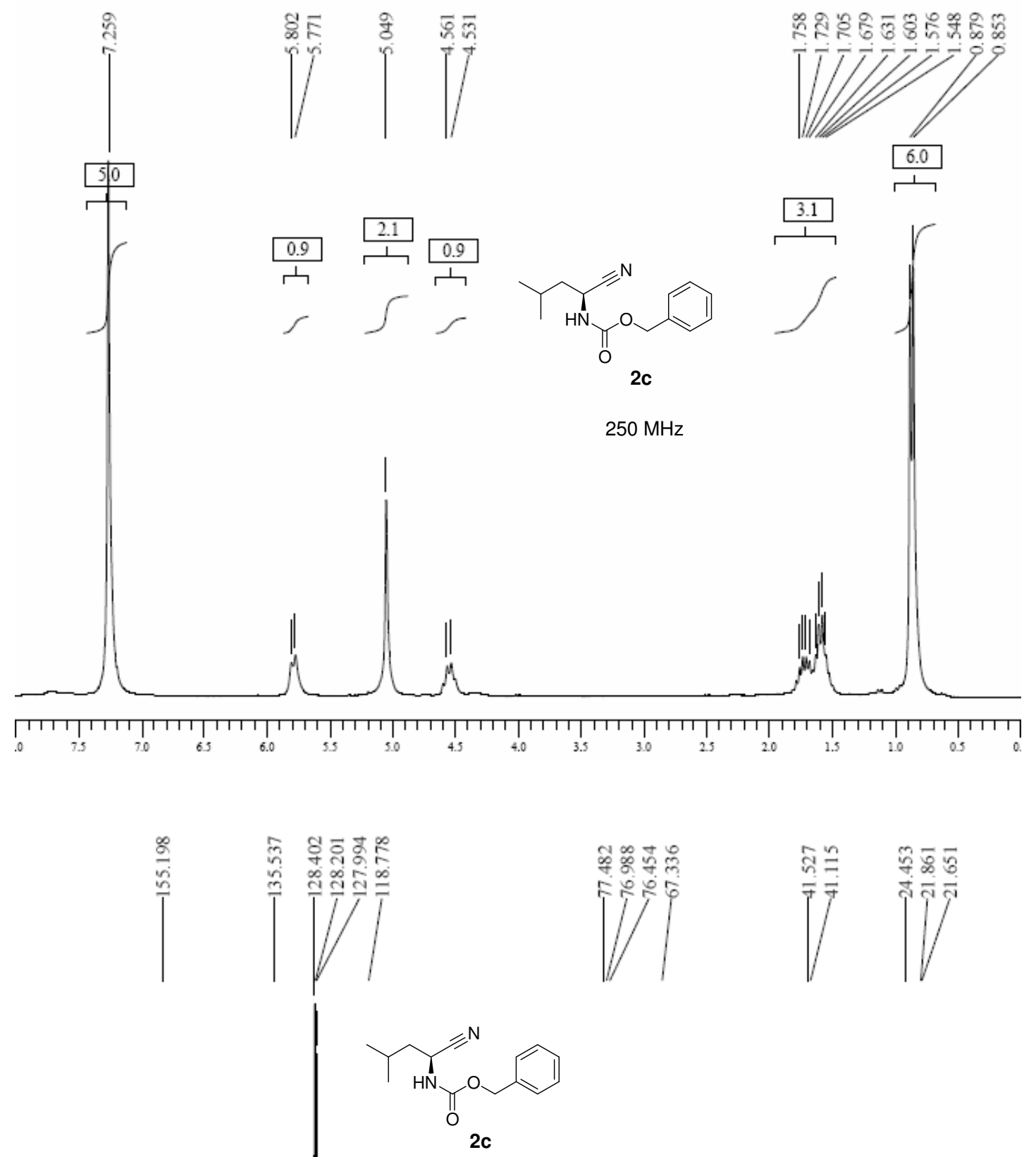

$62.5 \mathrm{MHz}$

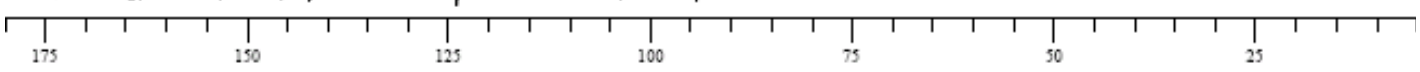



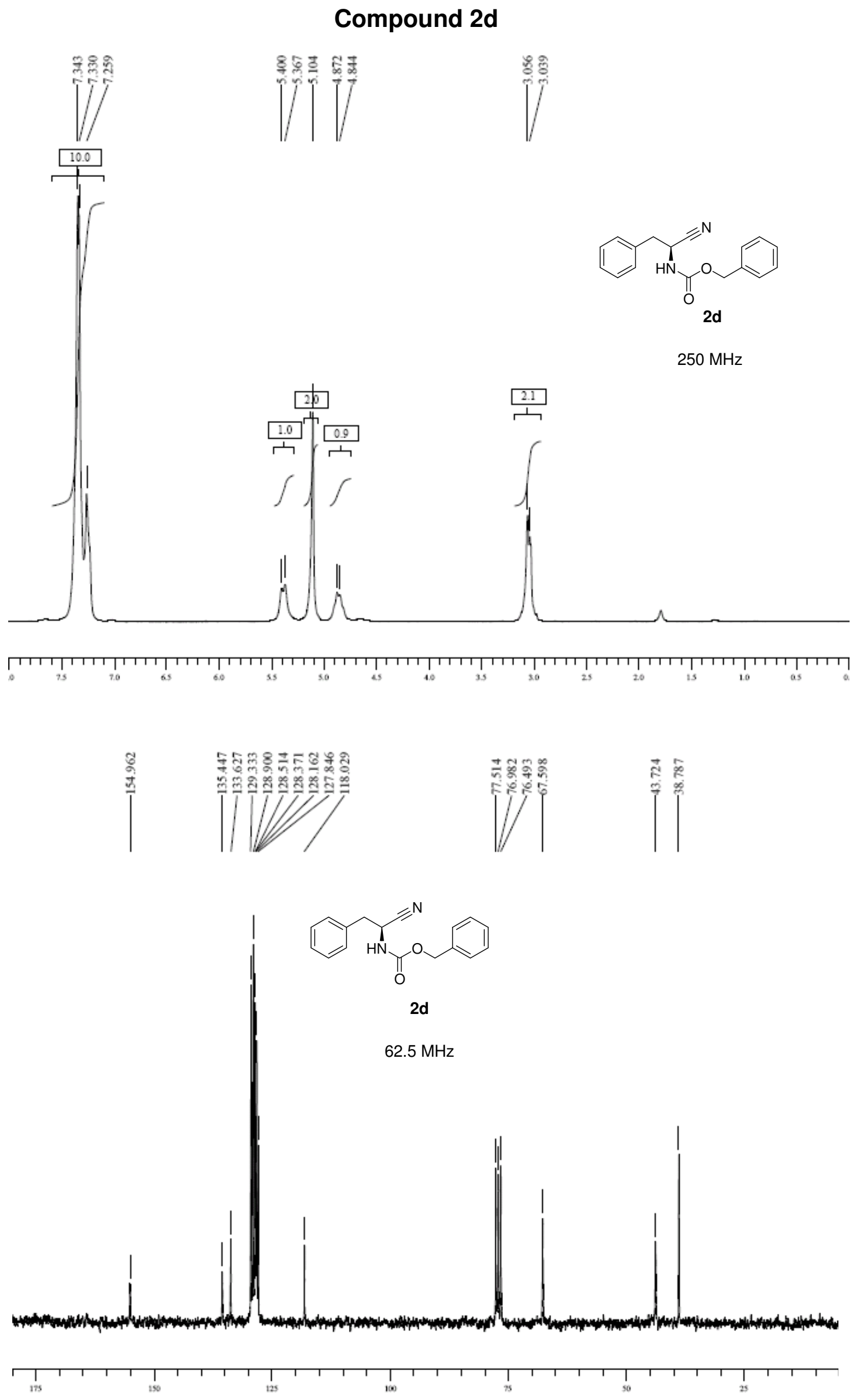

5 
Compound $3 a$

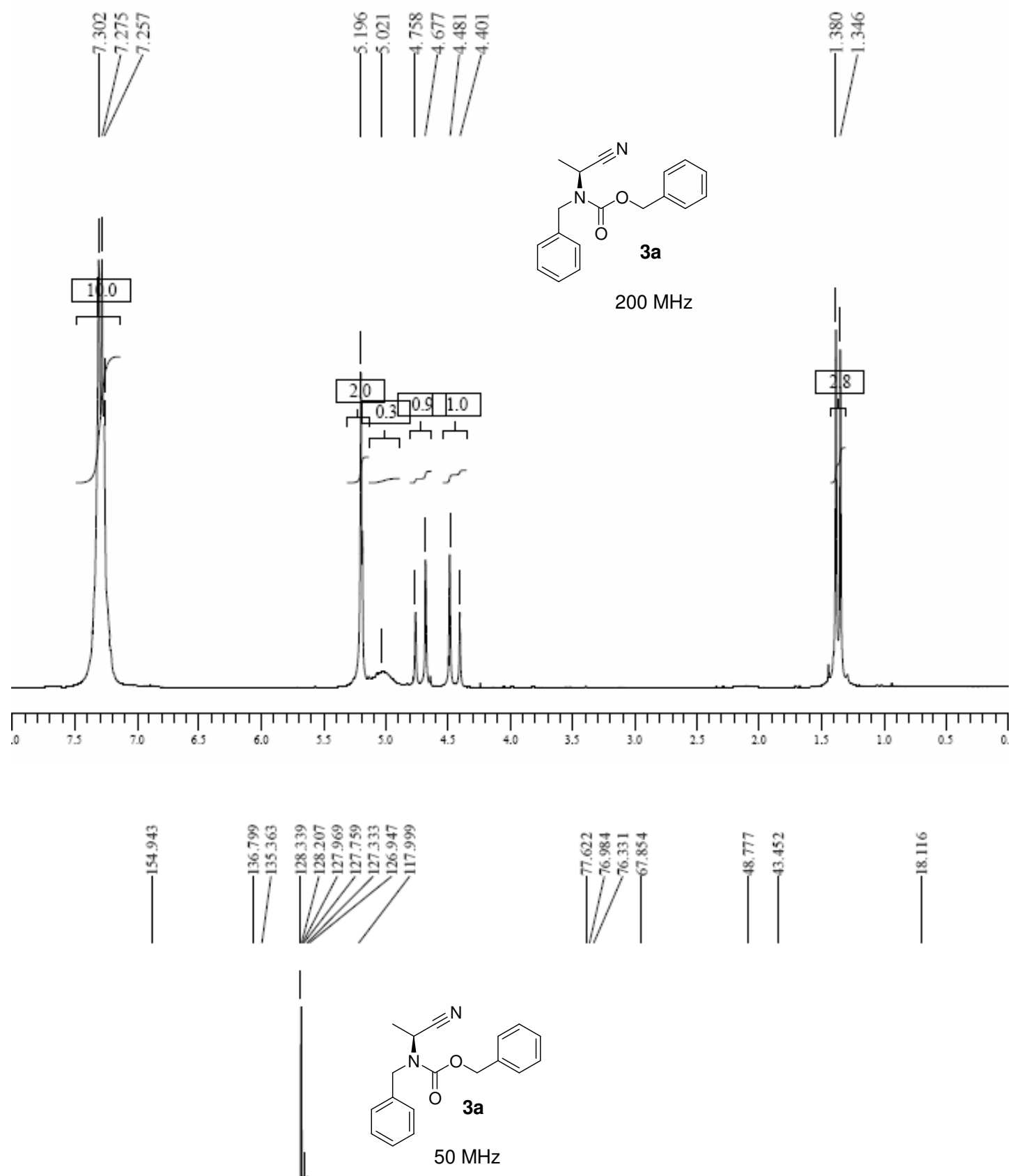




\section{Compound $3 \mathrm{~b}$}
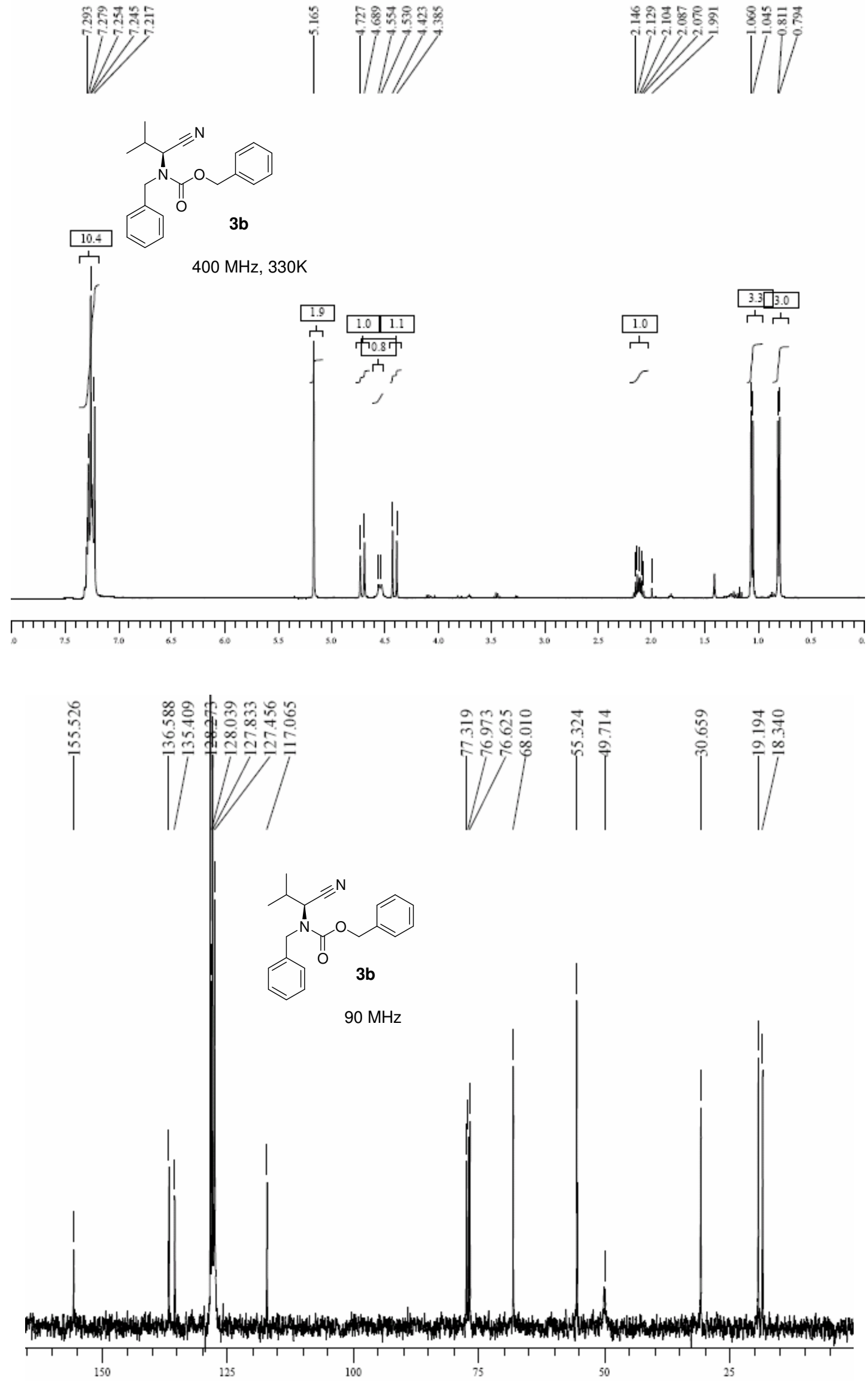

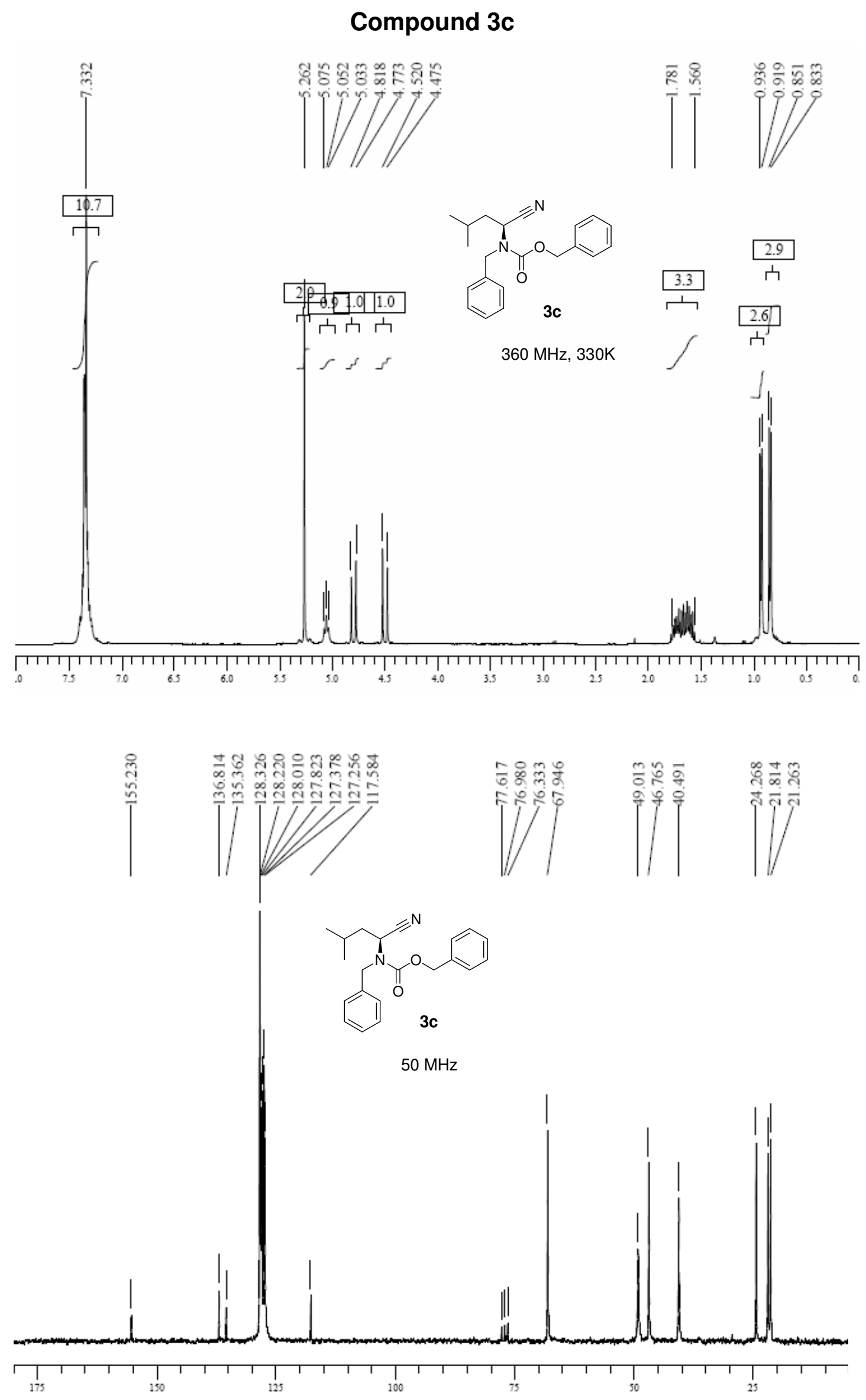

8 
Compound 3d
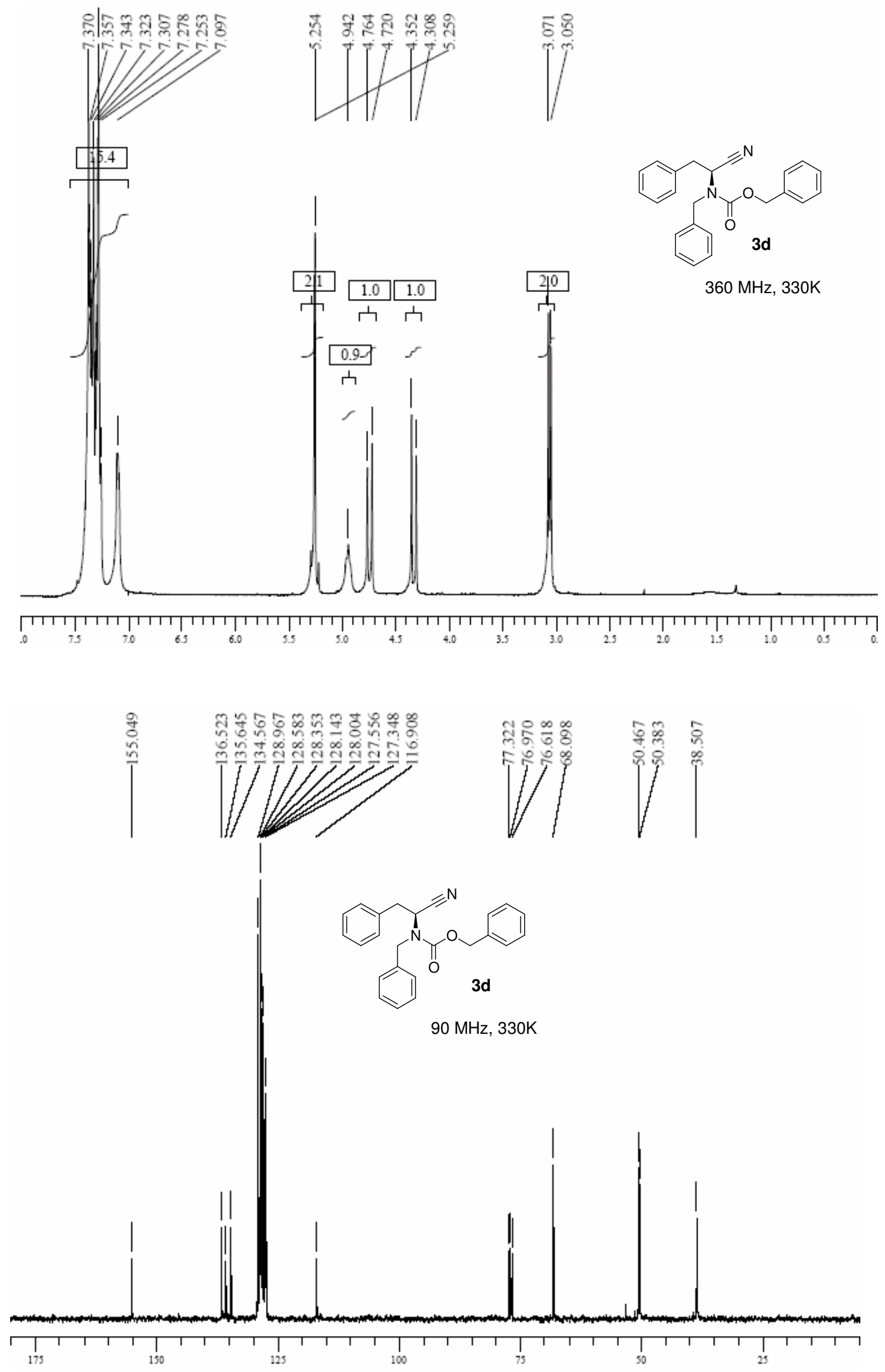


\section{Compound 5a}

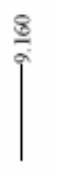

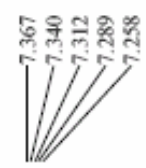
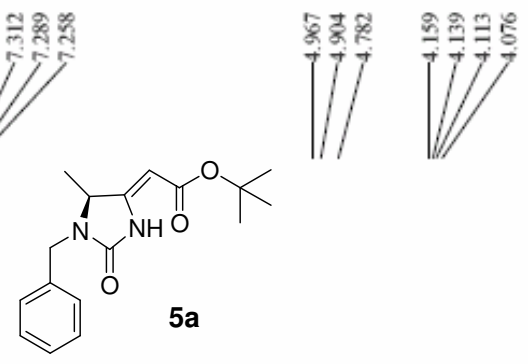

$250 \mathrm{MHz}$
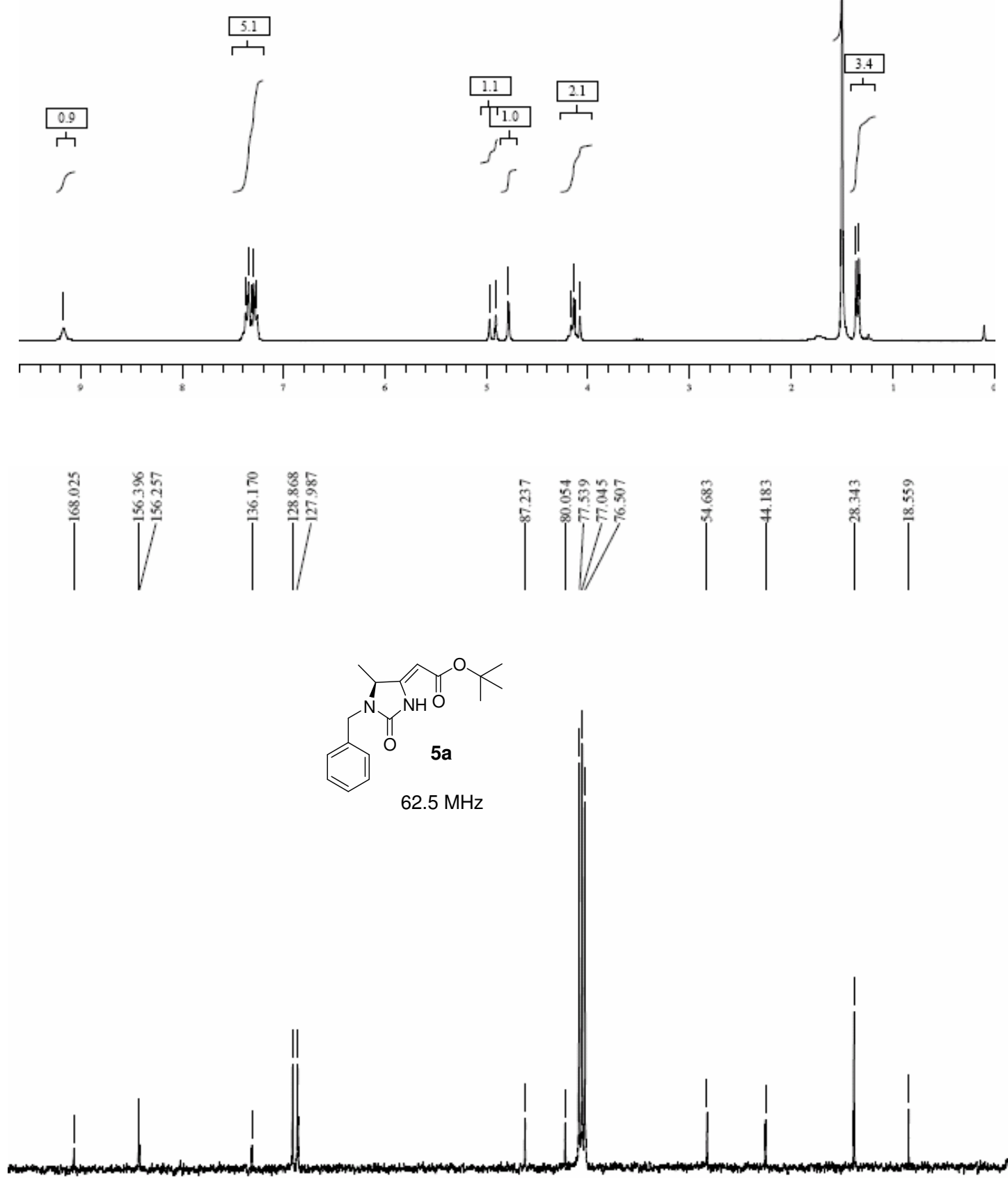

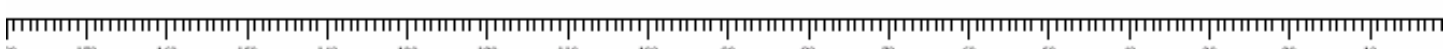


Compound 5b
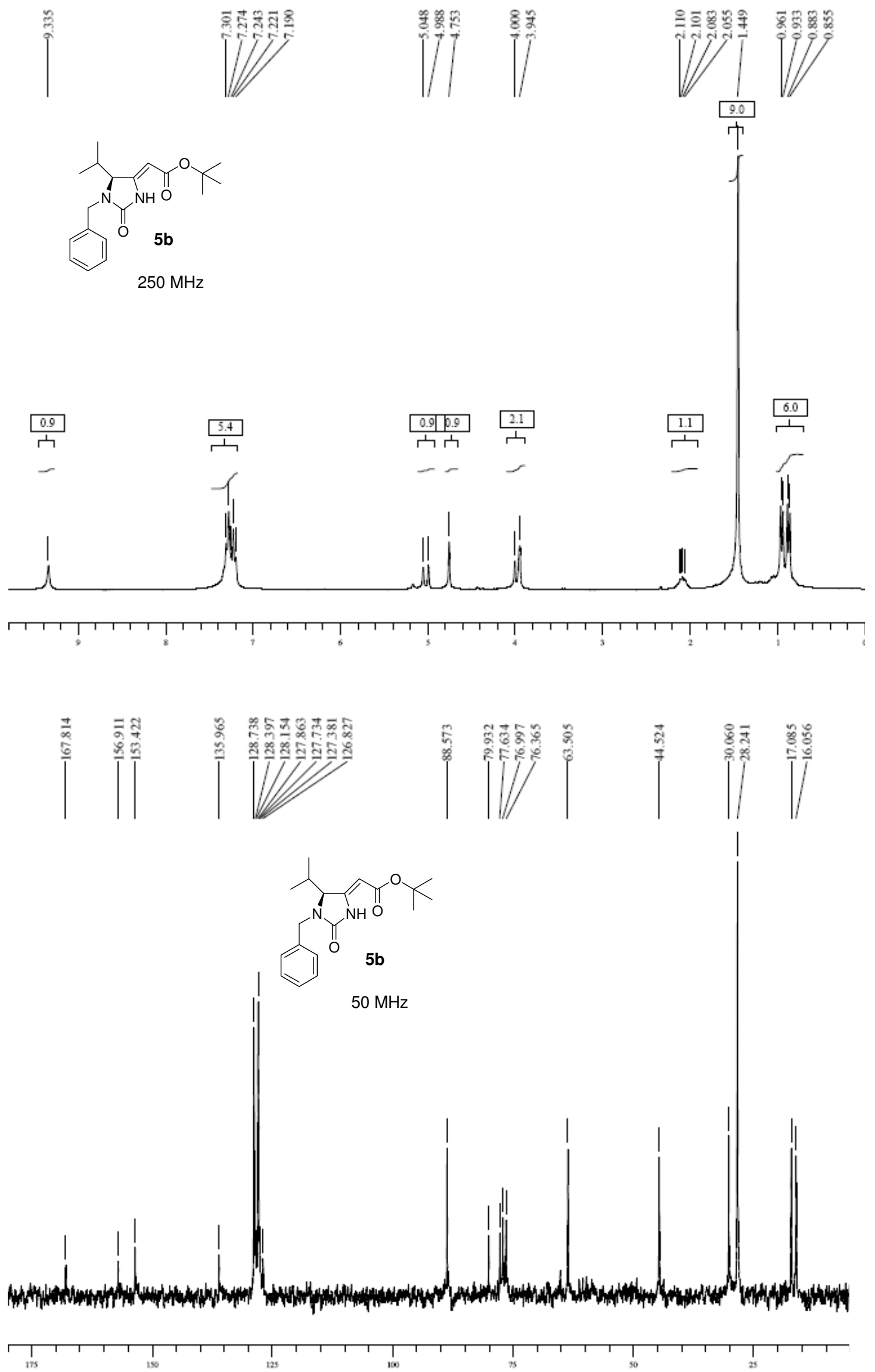
Compound 5c

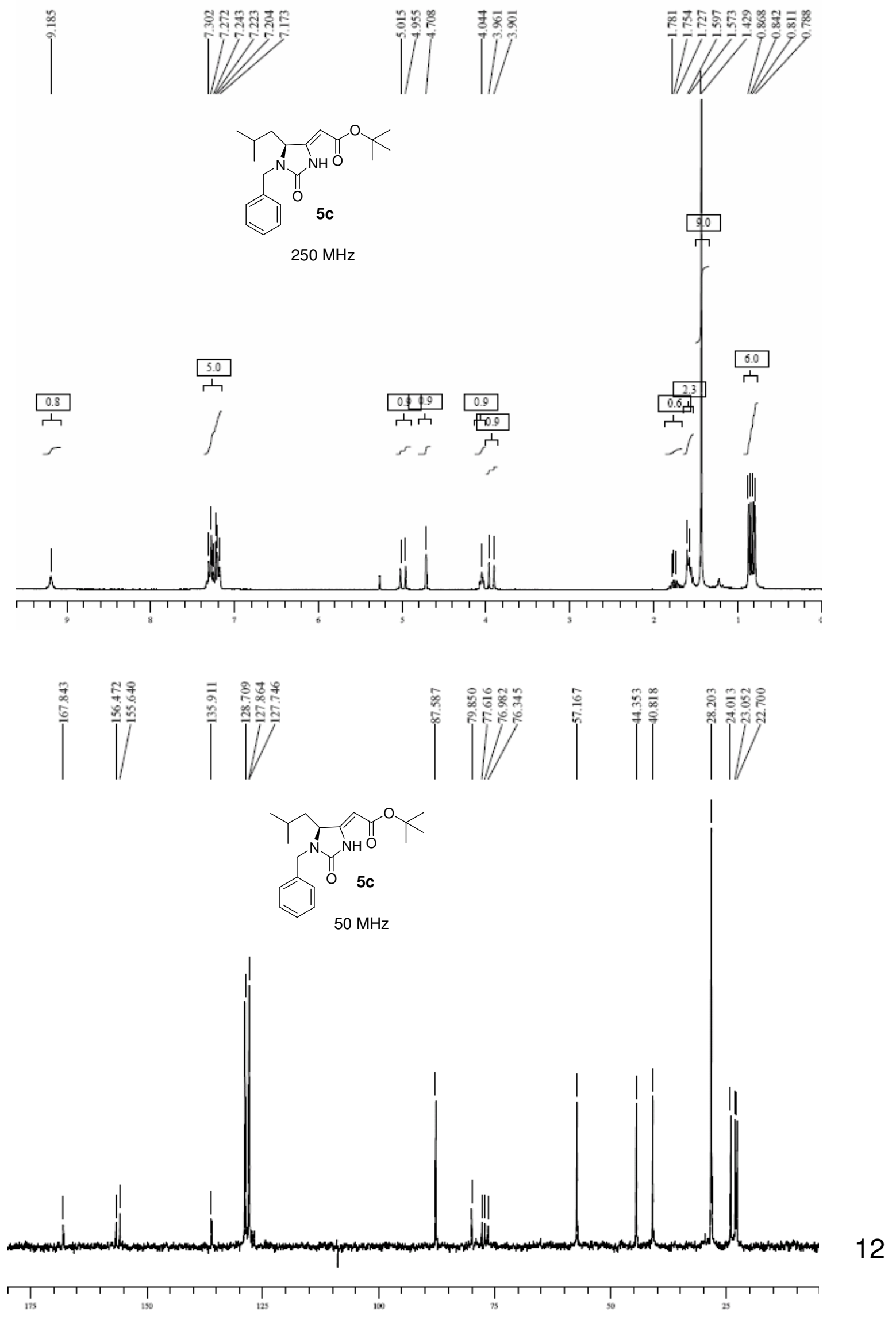




\section{Compound 5d}
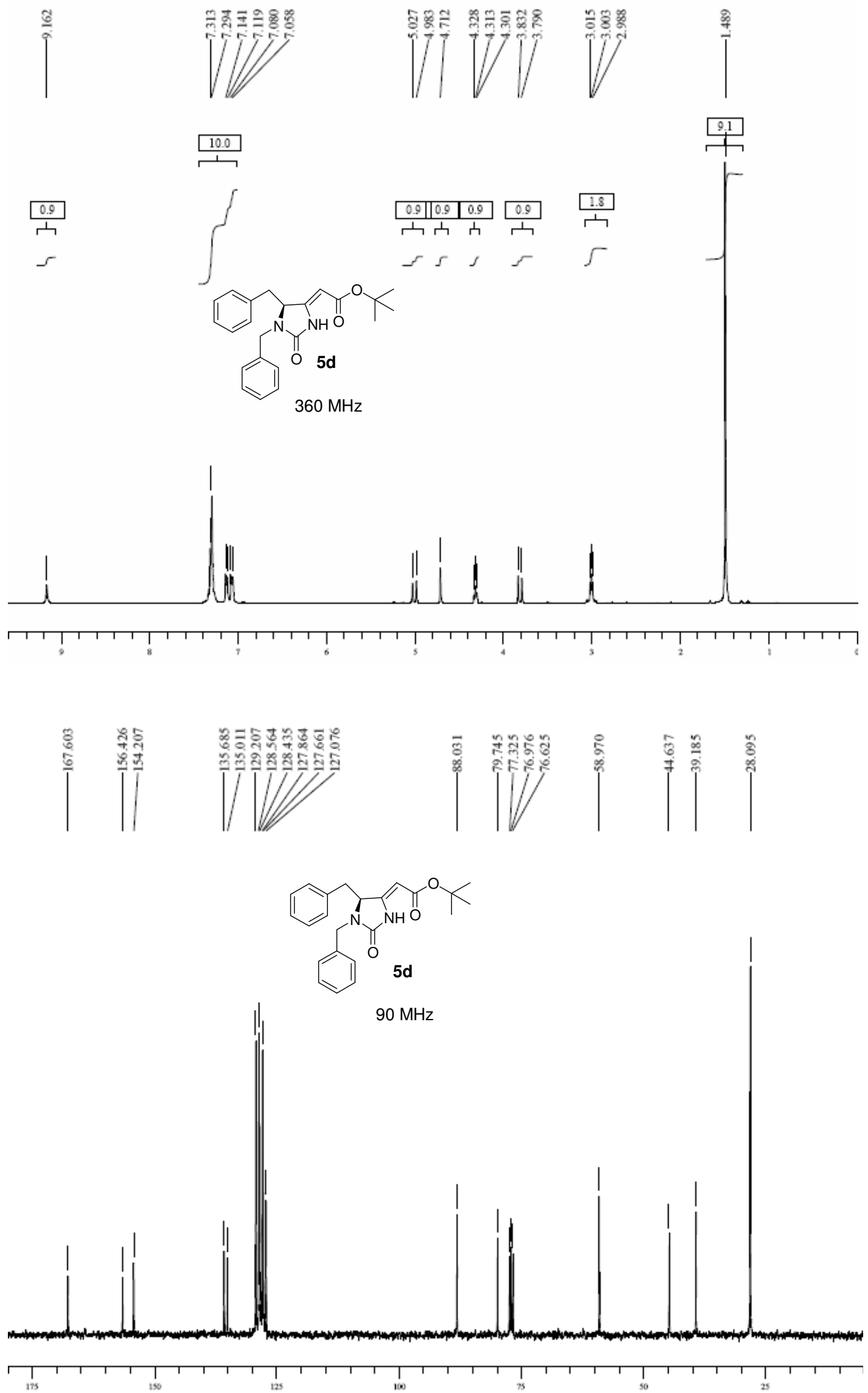


\section{Compound $5 e$}

है
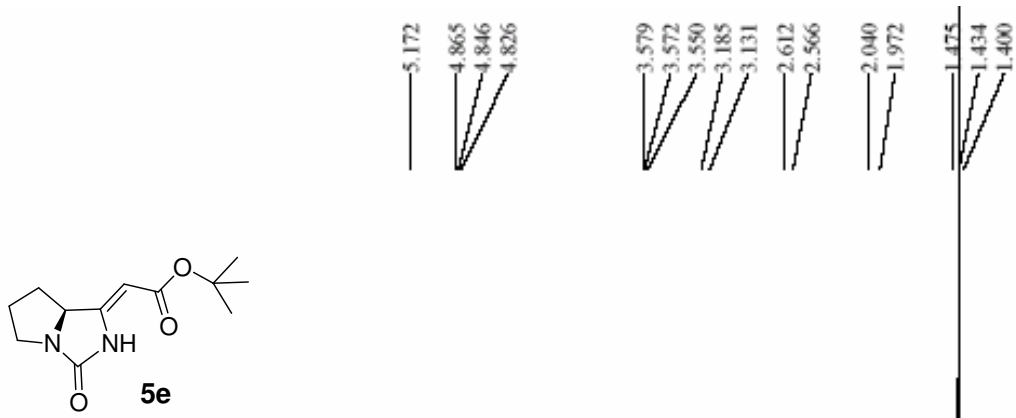

$360 \mathrm{MHz}$
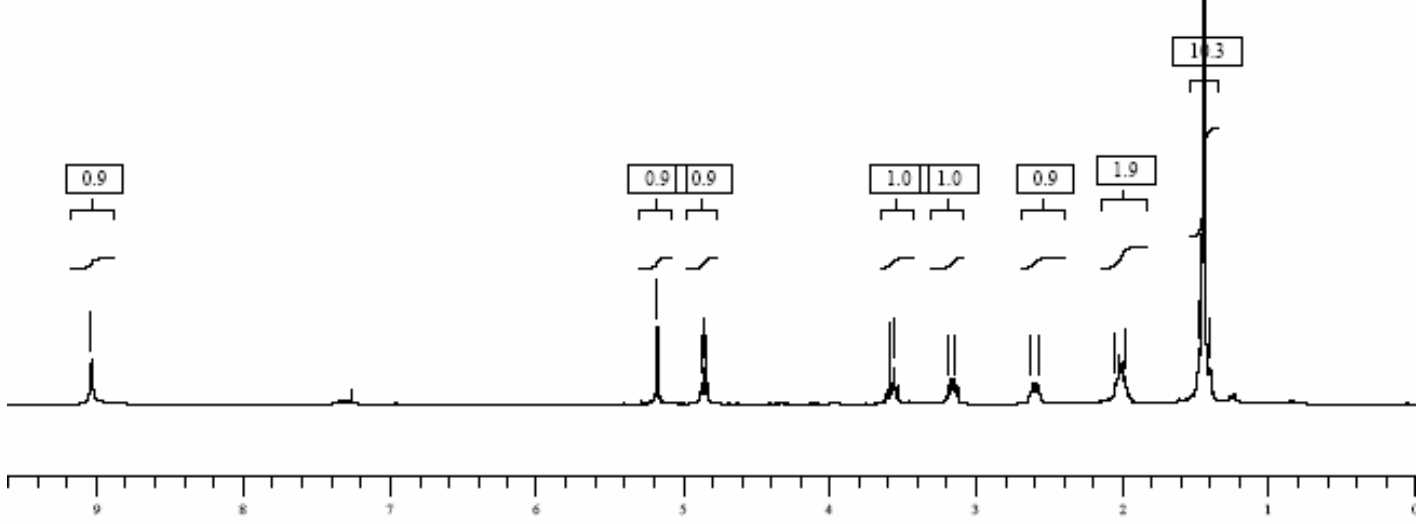

$\prod^{\infty}=$
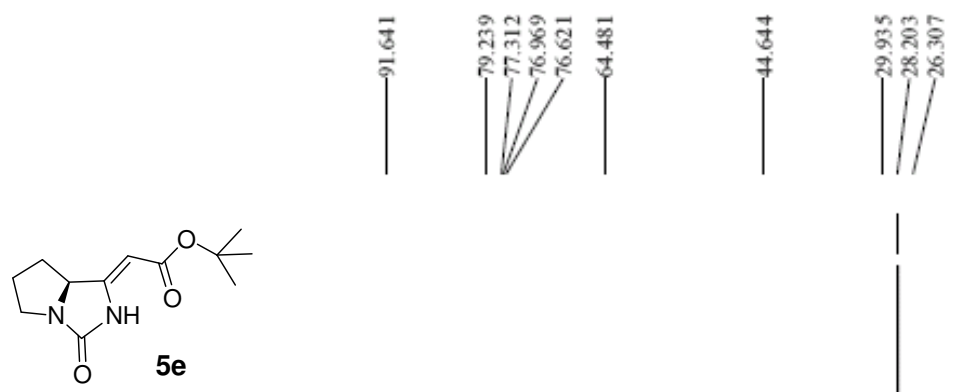

$90 \mathrm{MHz}$

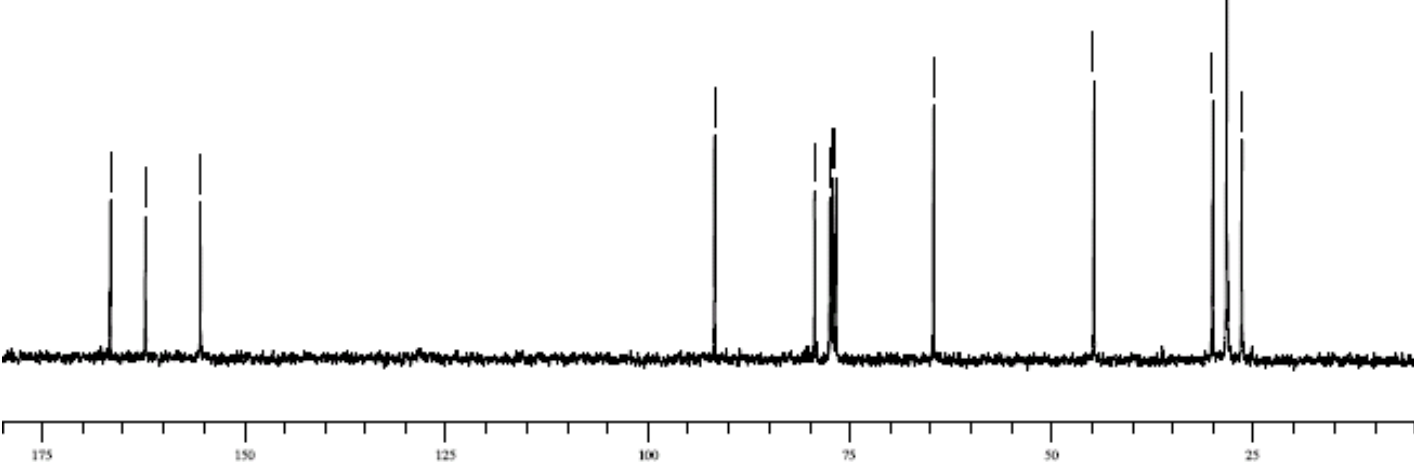


Compound $6 \mathrm{~b}$
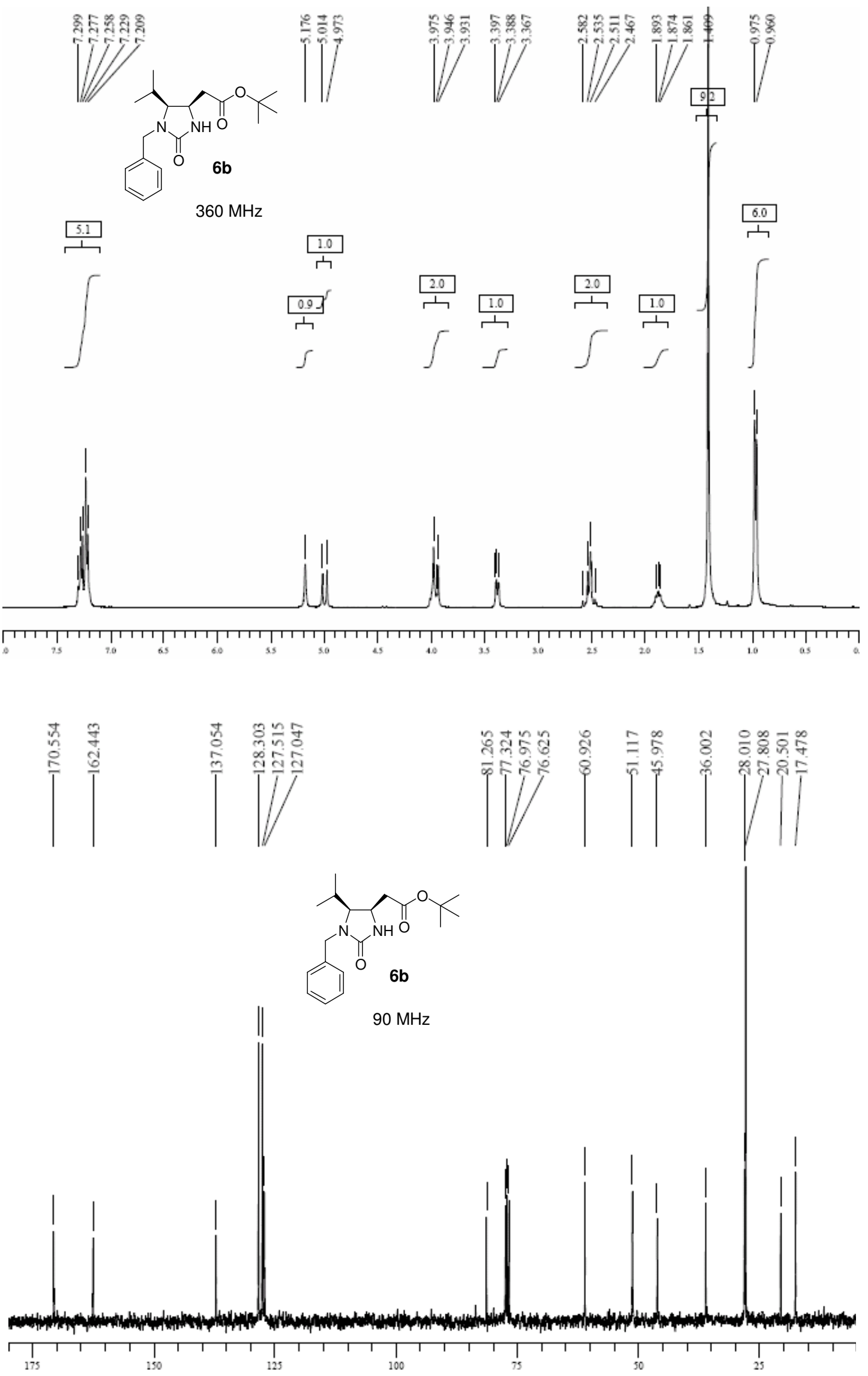
Compound 6c cis isomer
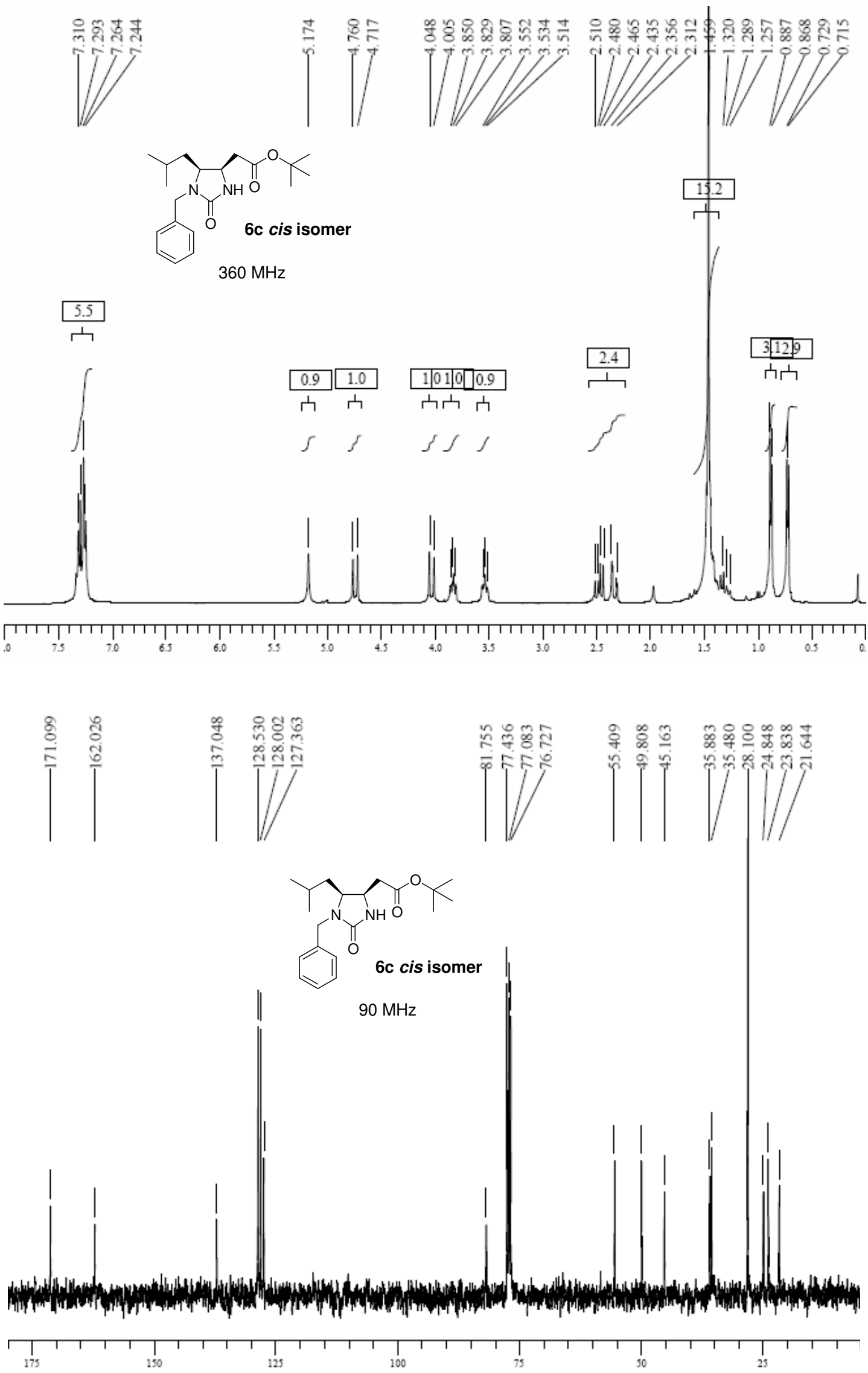


\section{Compound 6c trans isomer}

ตำ
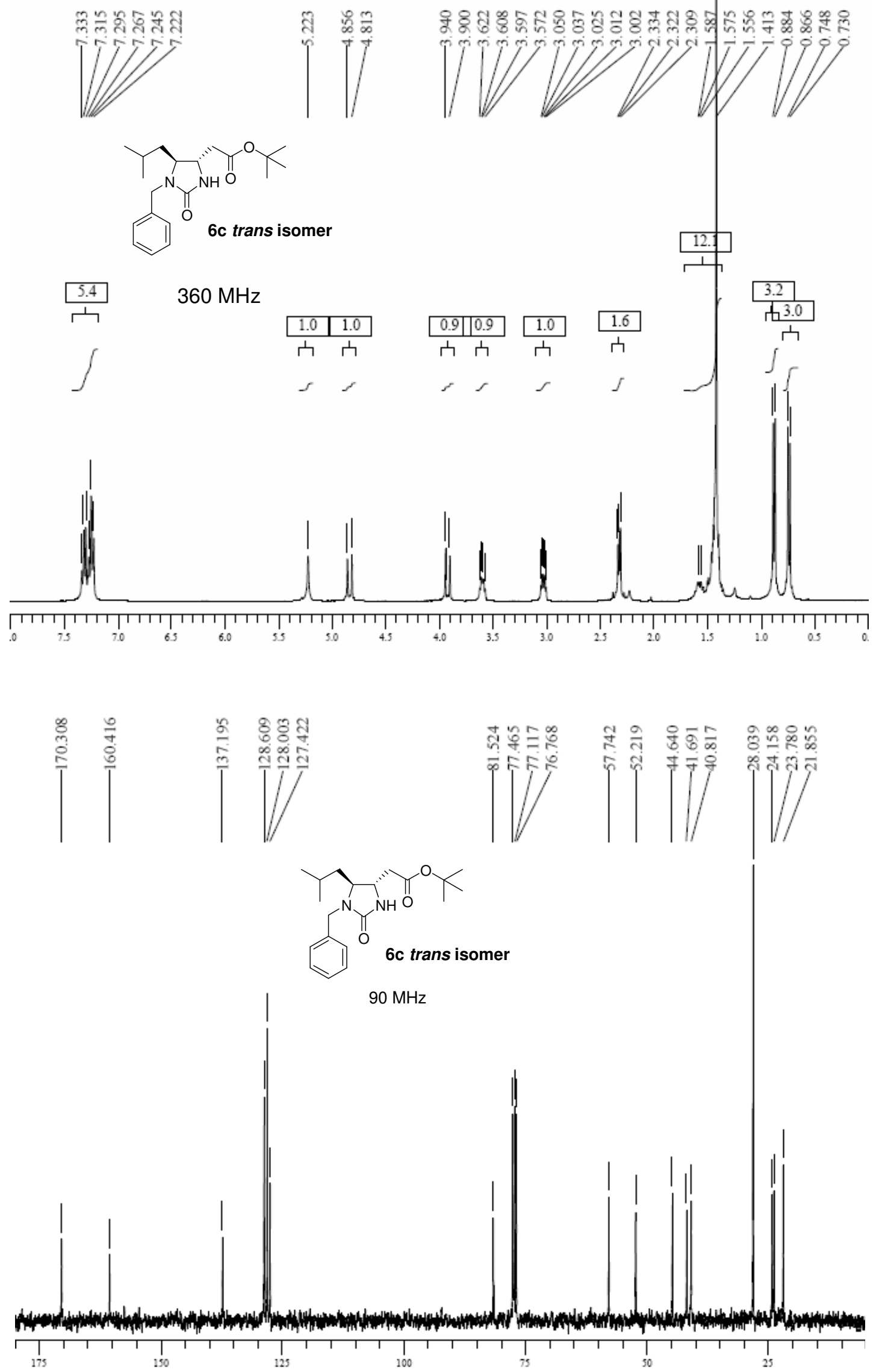
Compound 6d cis isomer

1/

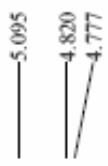

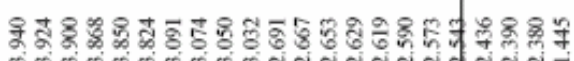
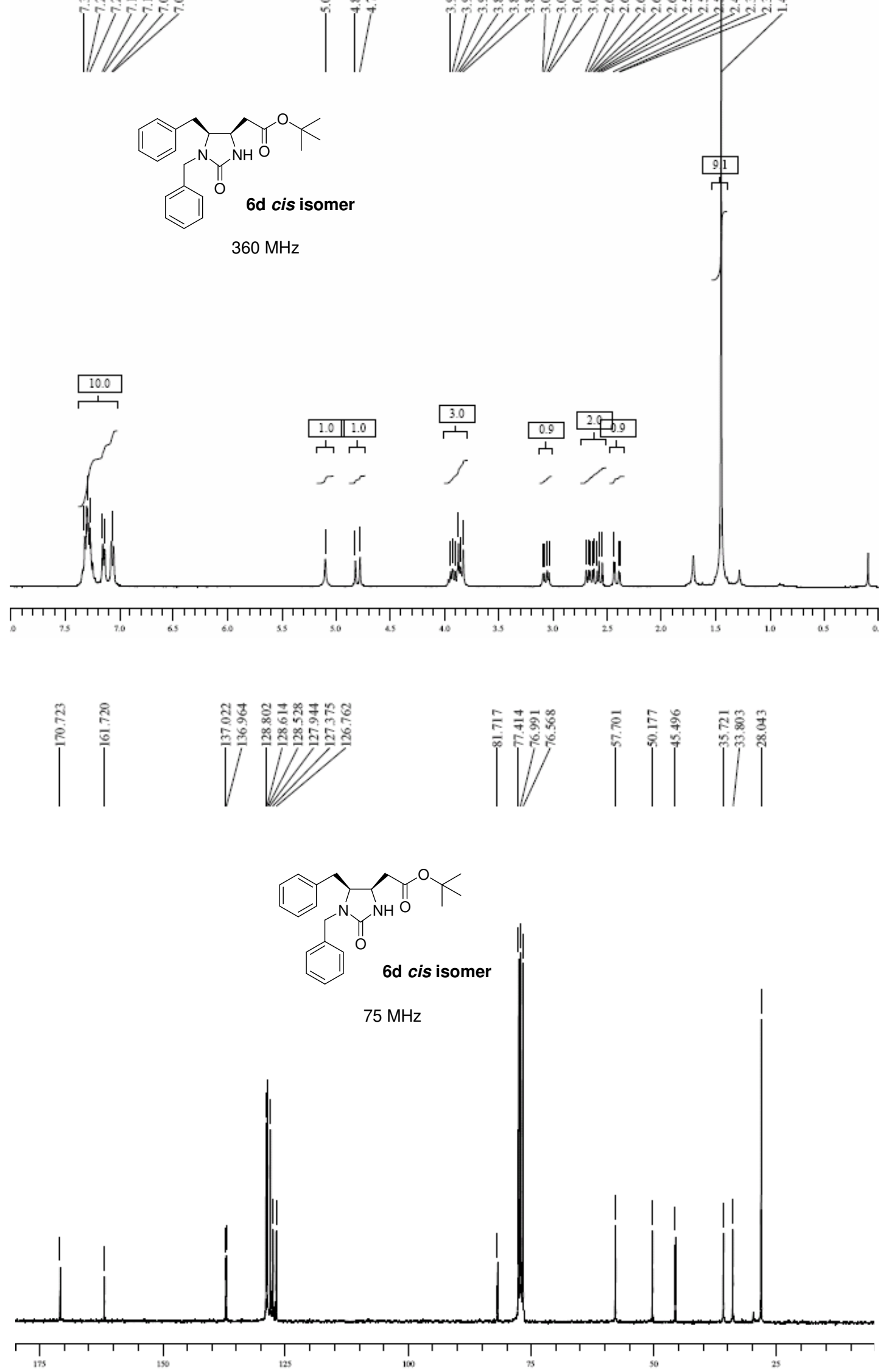
Compound 6d trans isomer

50
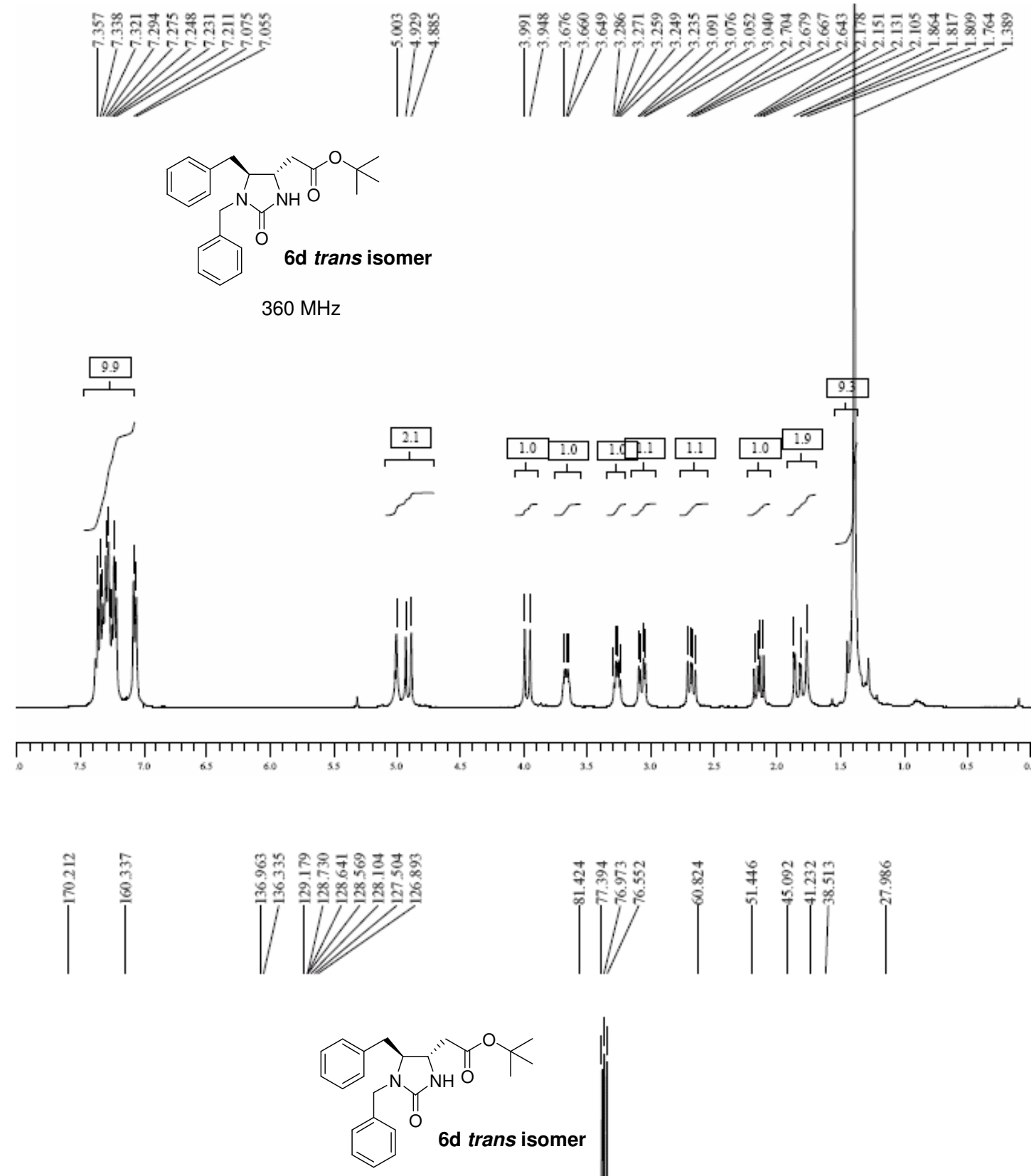

$75 \mathrm{MHz}$

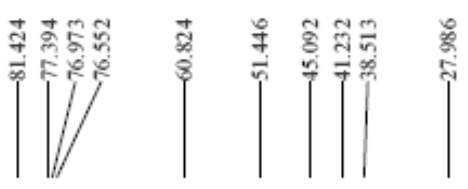

75 


\section{Compound 8a}
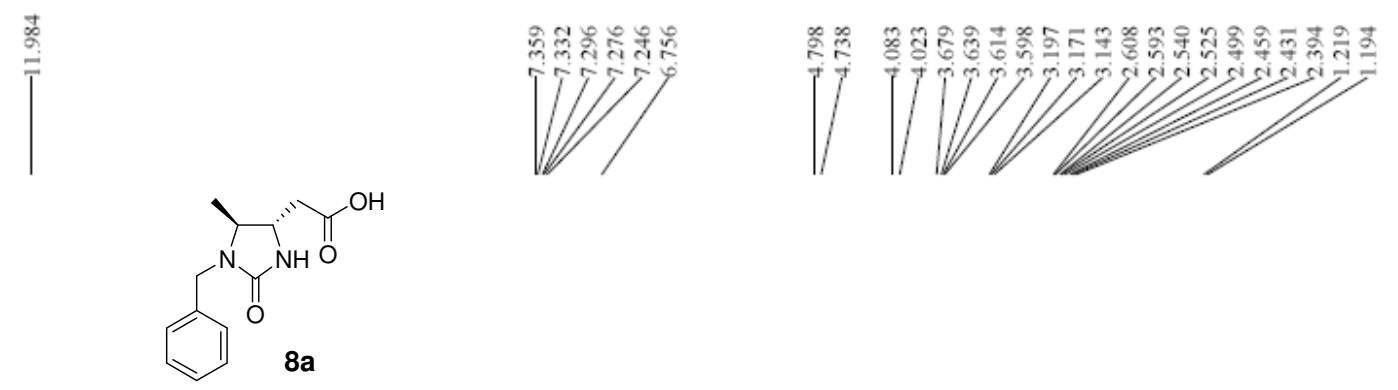

$250 \mathrm{MHz}$

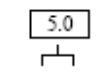
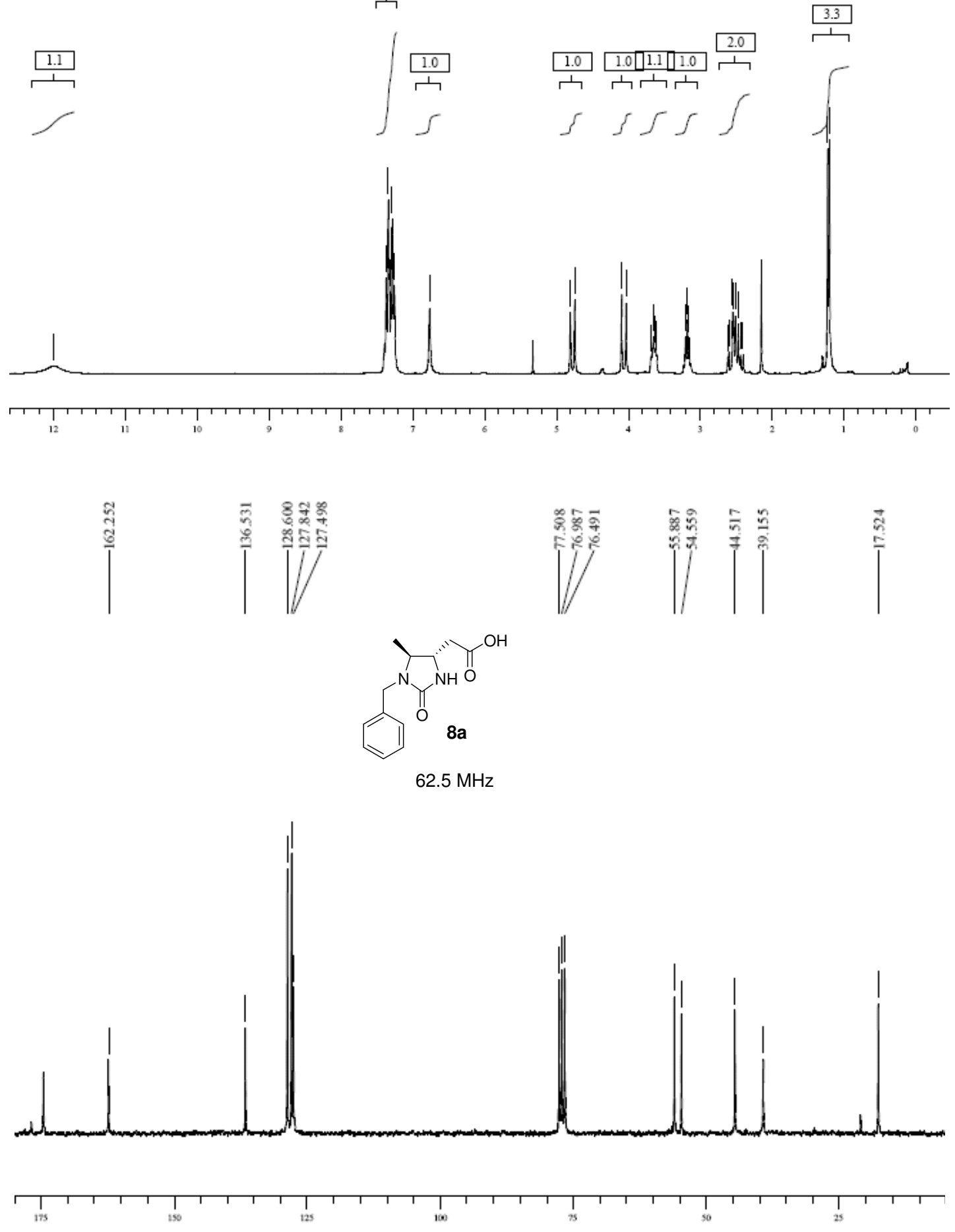


\section{Compound 9a}
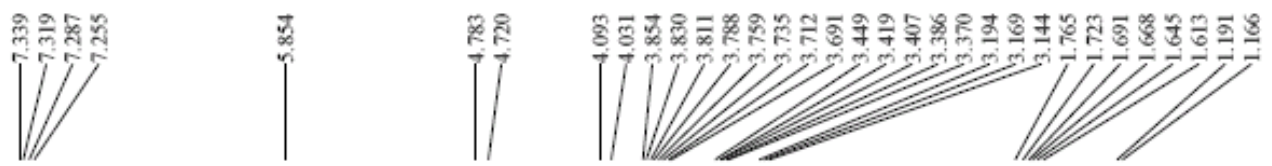<smiles>CC1C(CCO)NC(=O)N1Cc1ccccc1</smiles>

$250 \mathrm{MHz}$
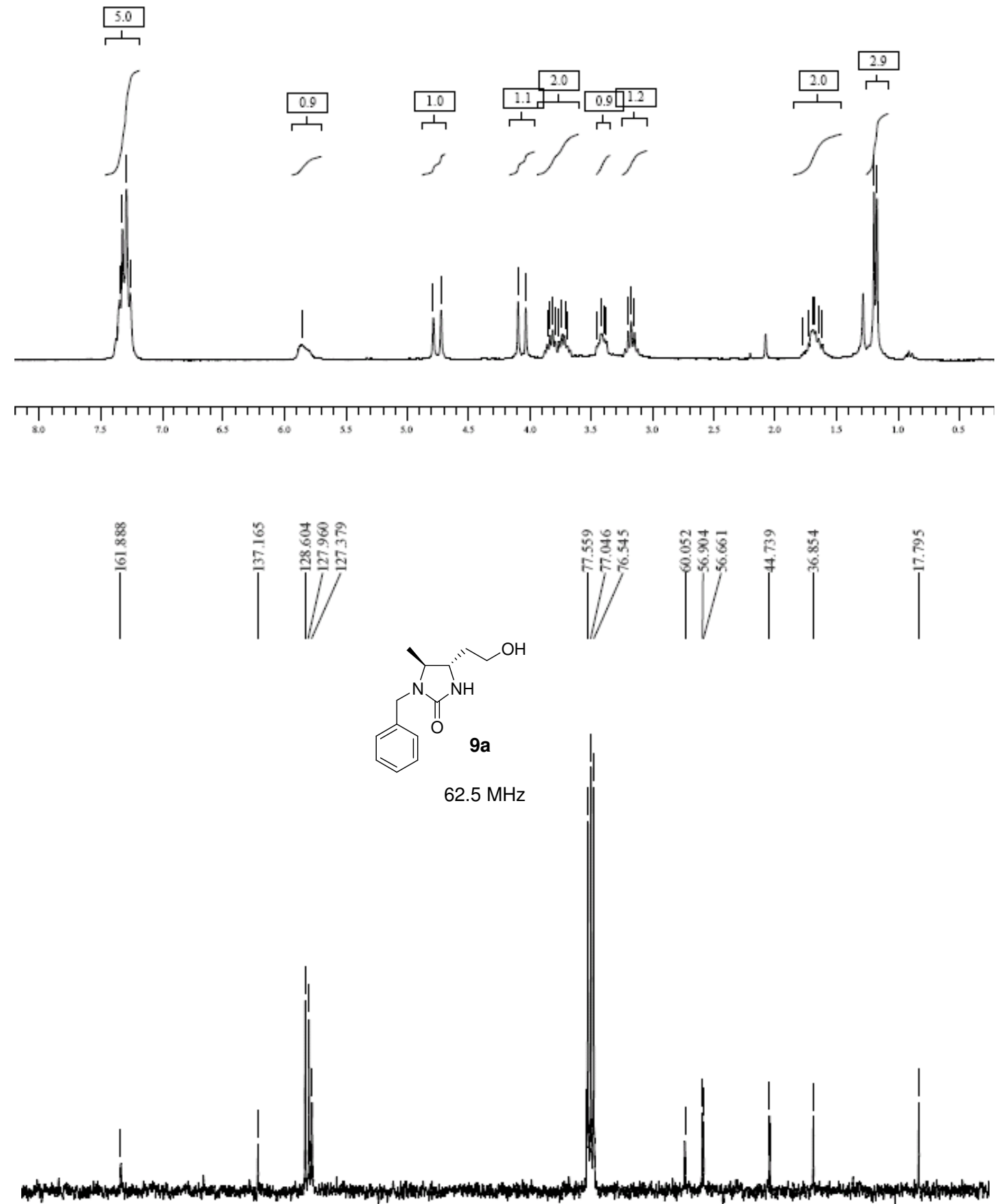
Compound $8 \mathrm{~b}$
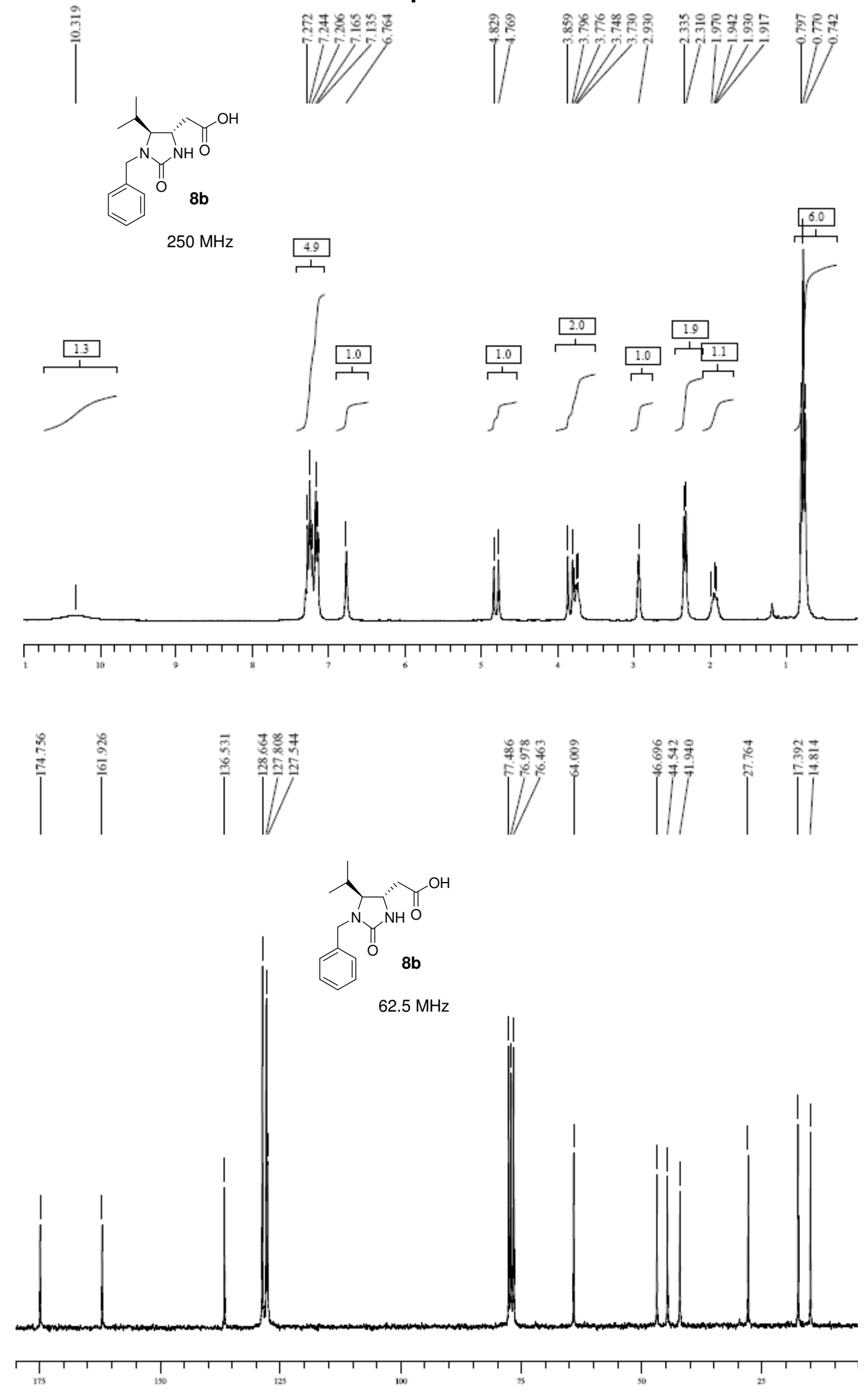


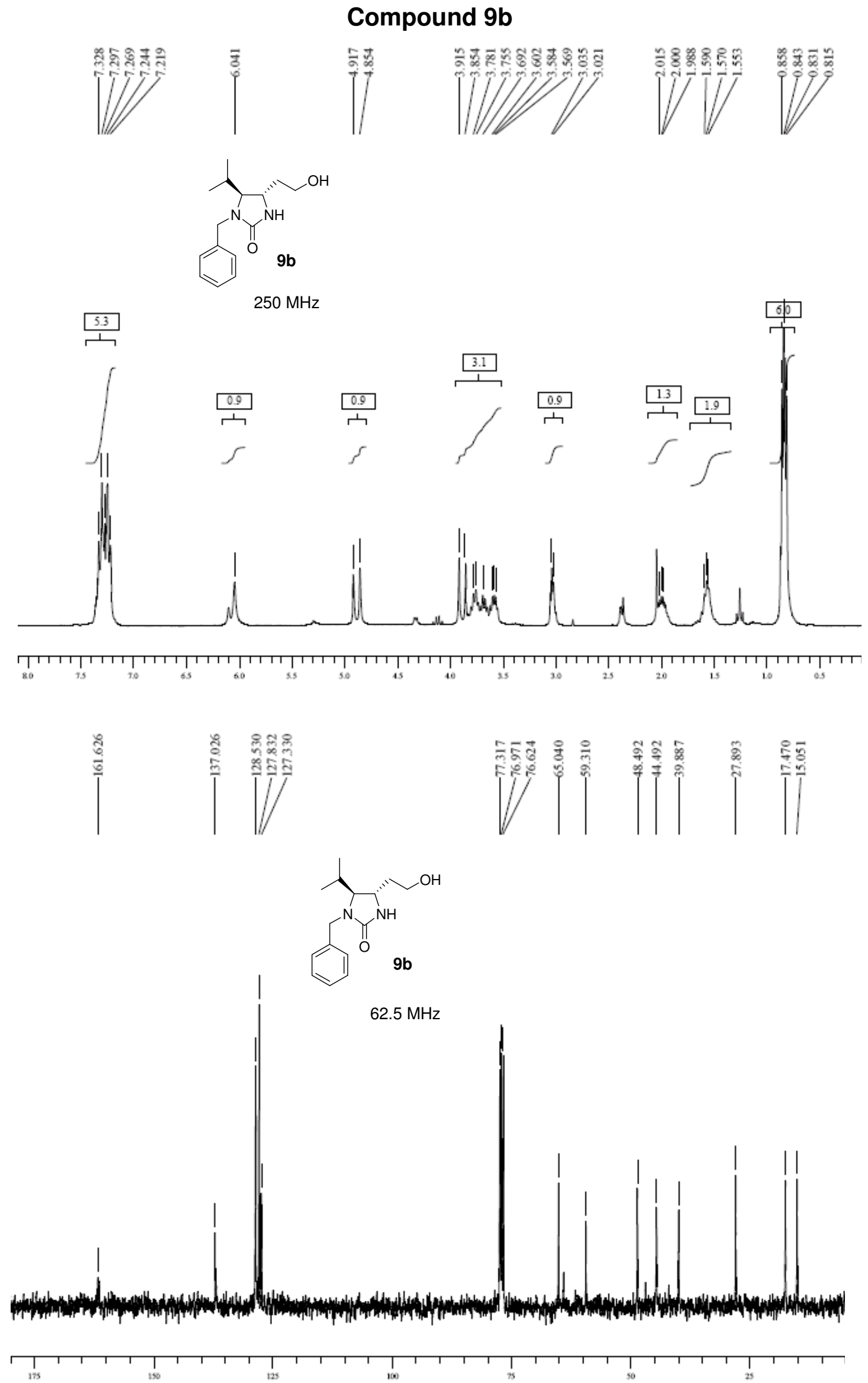


Compound $8 \mathrm{c}$
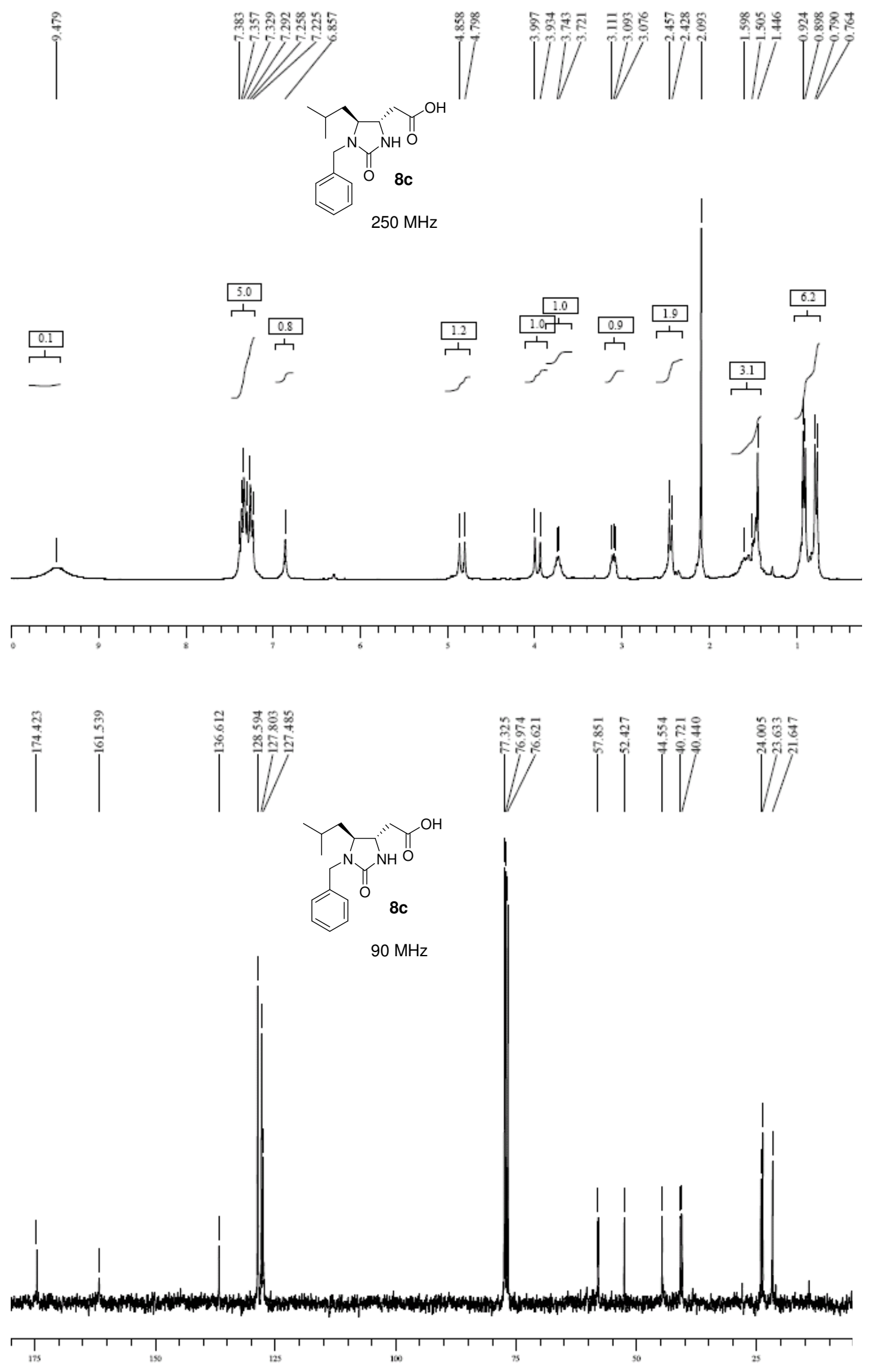


\section{Compound 9c}
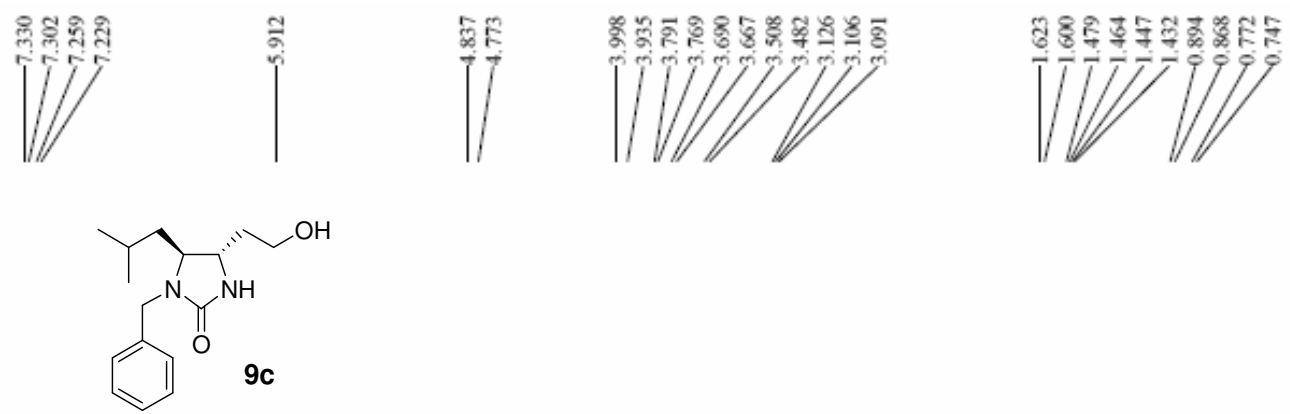

$250 \mathrm{MHz}$
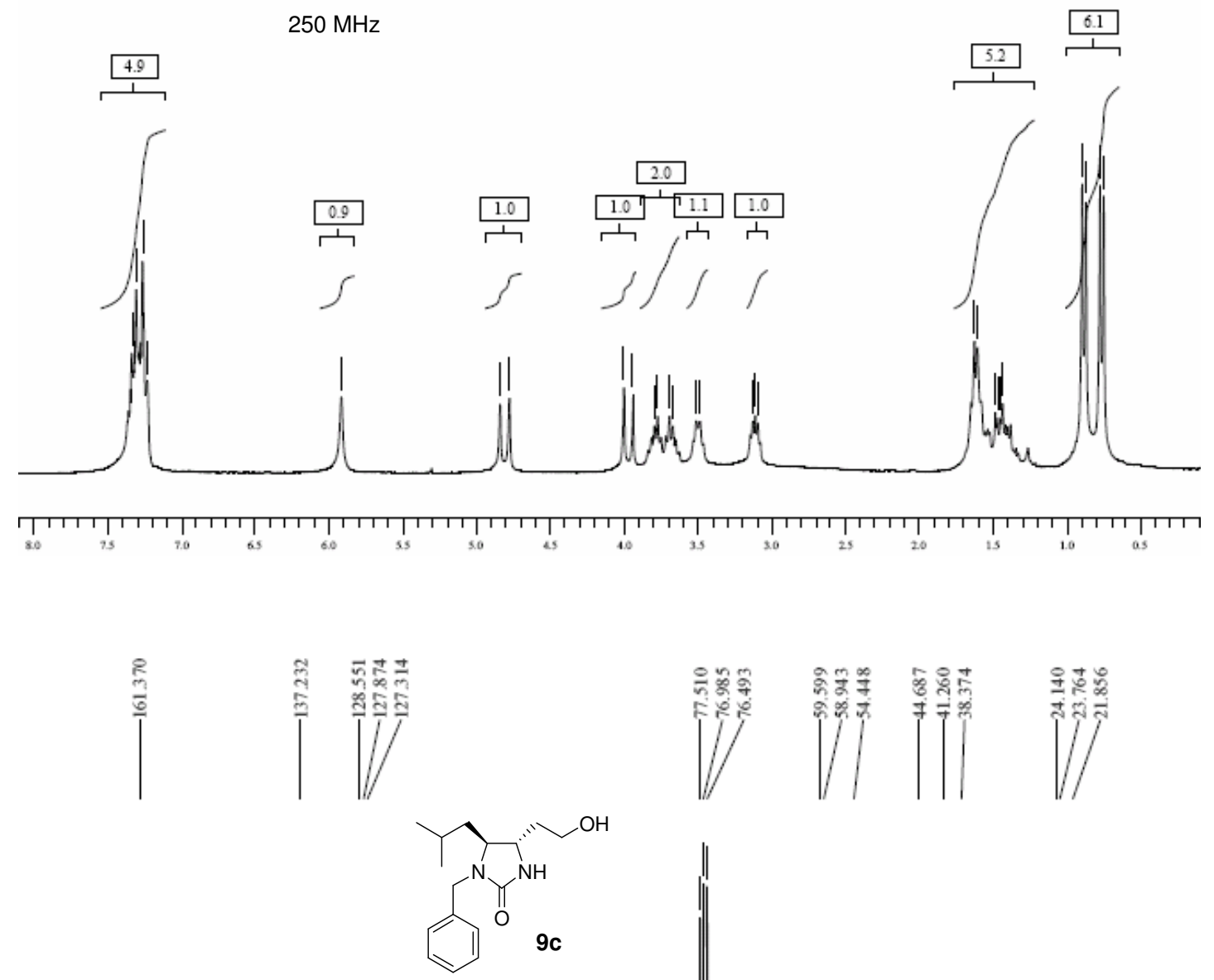

$62.5 \mathrm{MHz}$

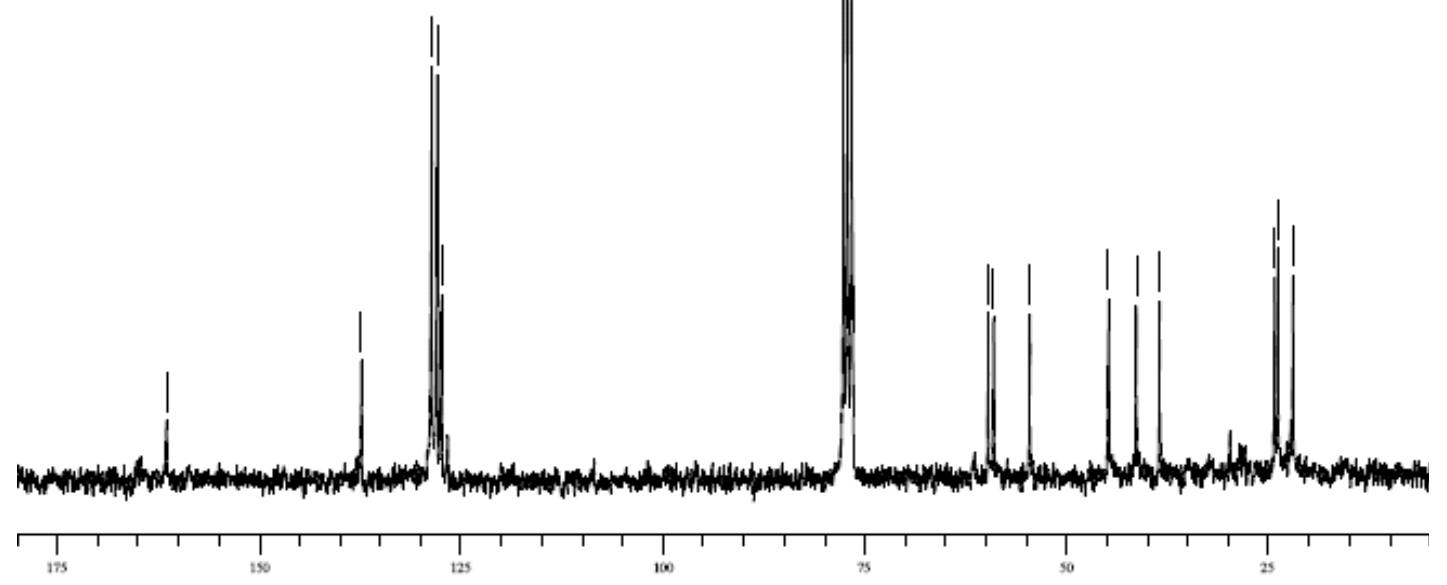




\section{Compound 8d}
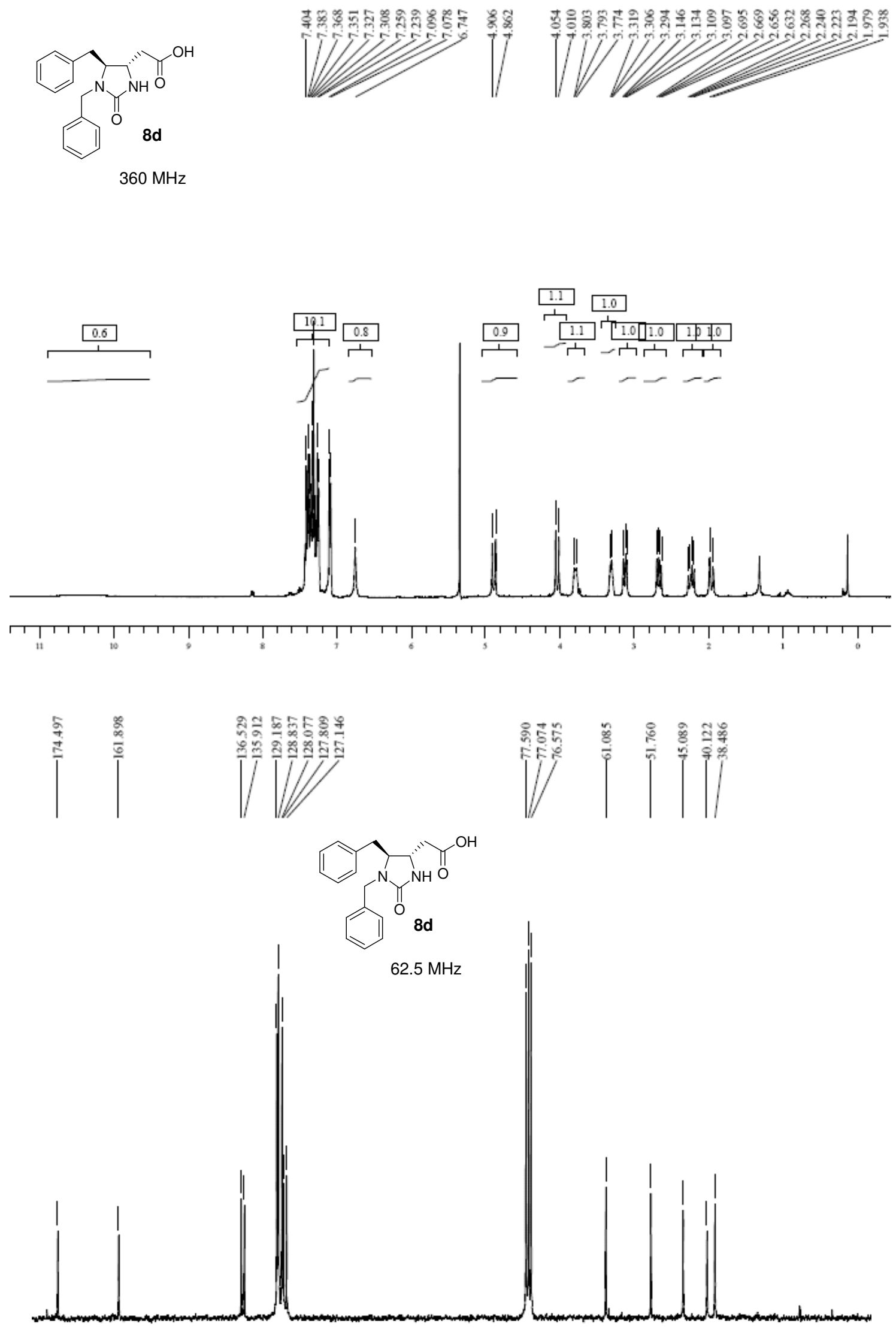


\section{Compound 9d}

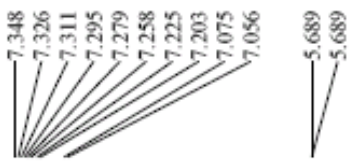
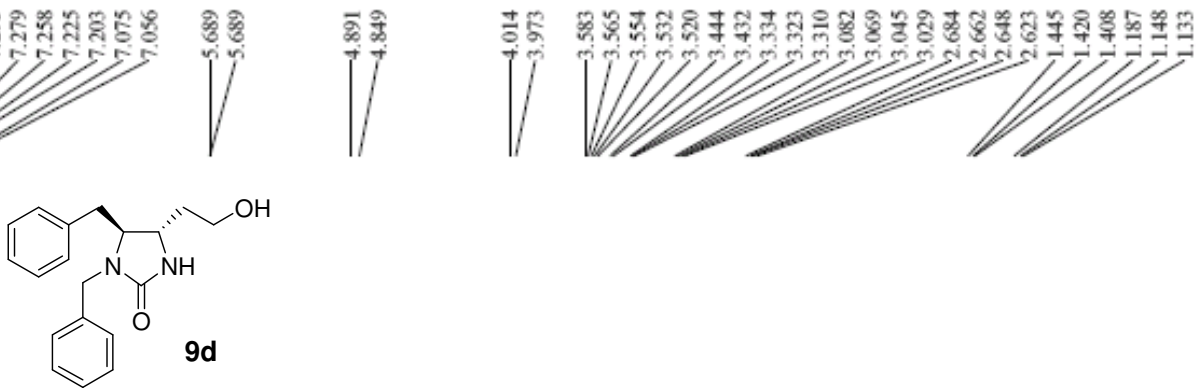

10.0

$360 \mathrm{MHz}$
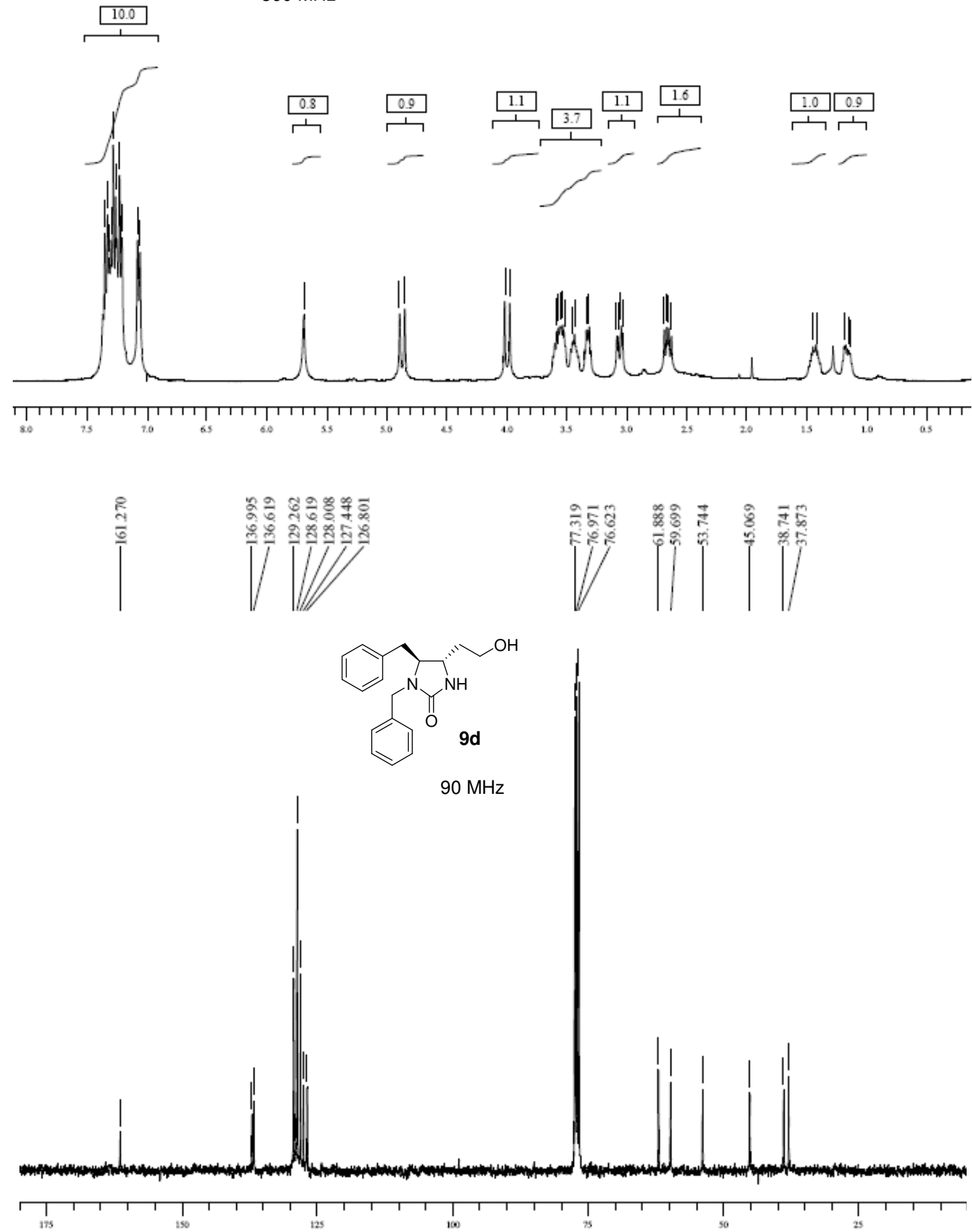


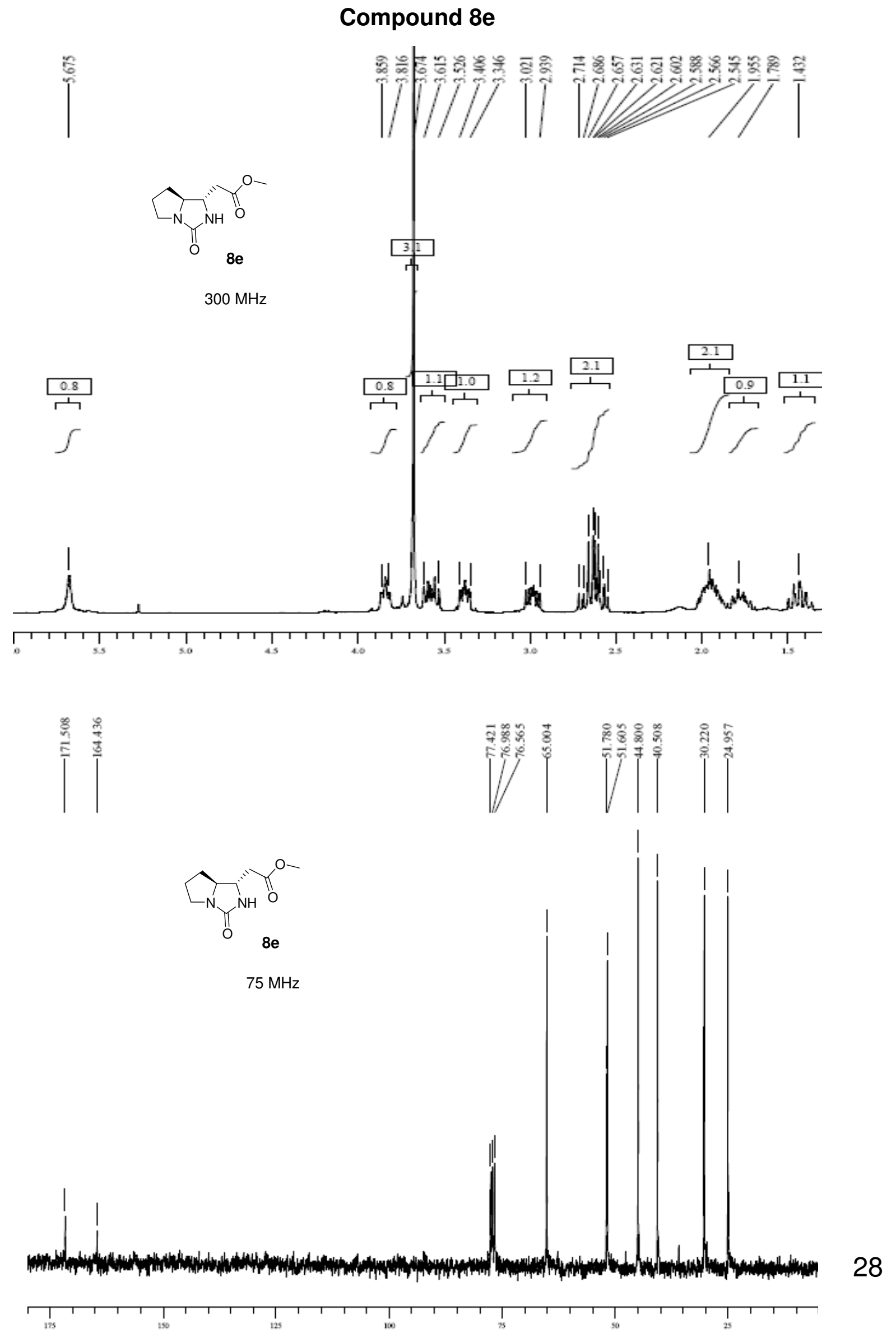




\section{Compound from saponification of $6 \mathrm{~b}$}
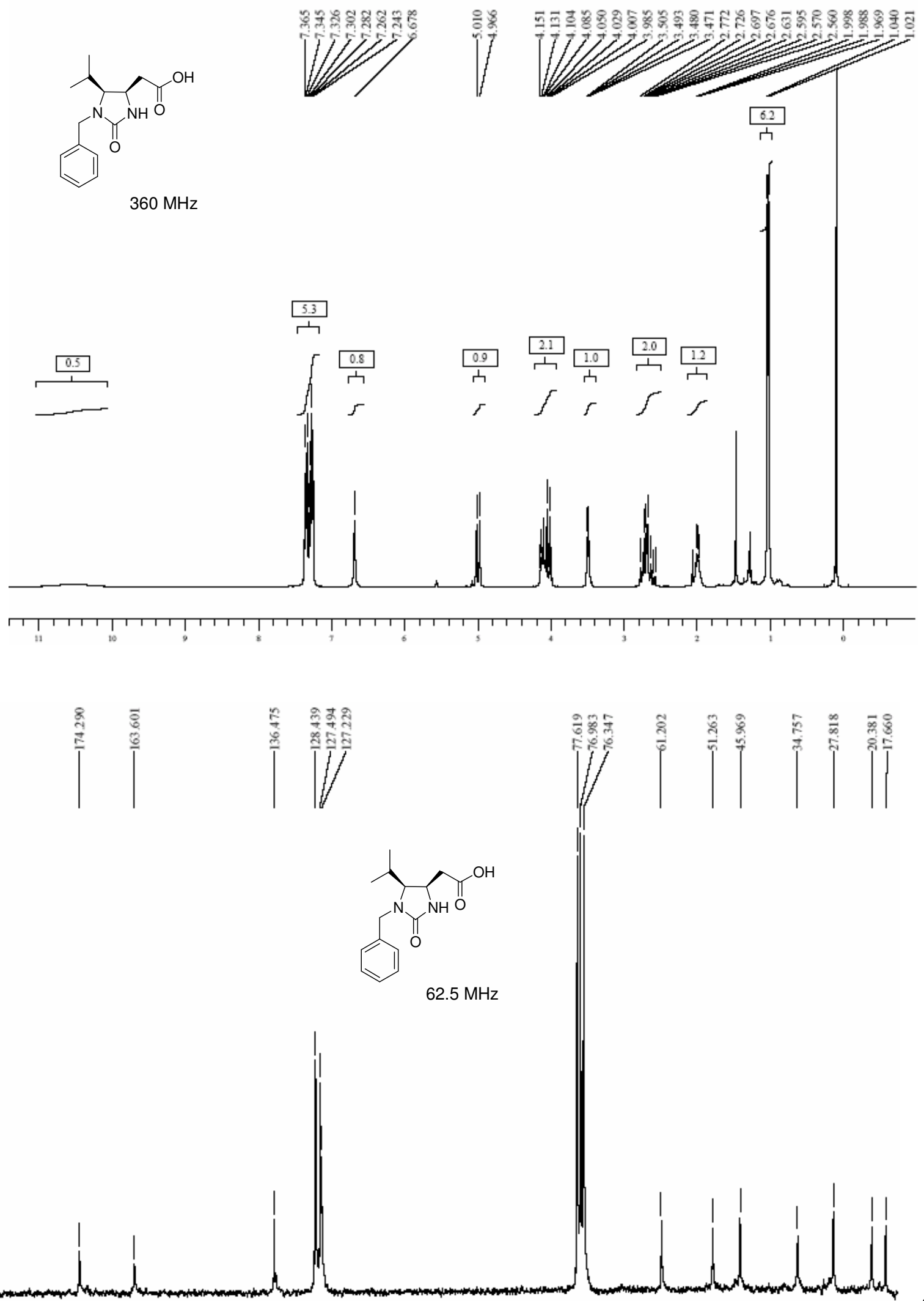


\section{Compound 7b}

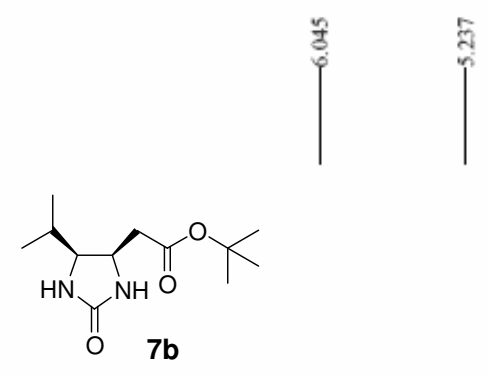

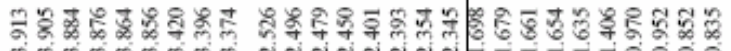

$360 \mathrm{MHz}$
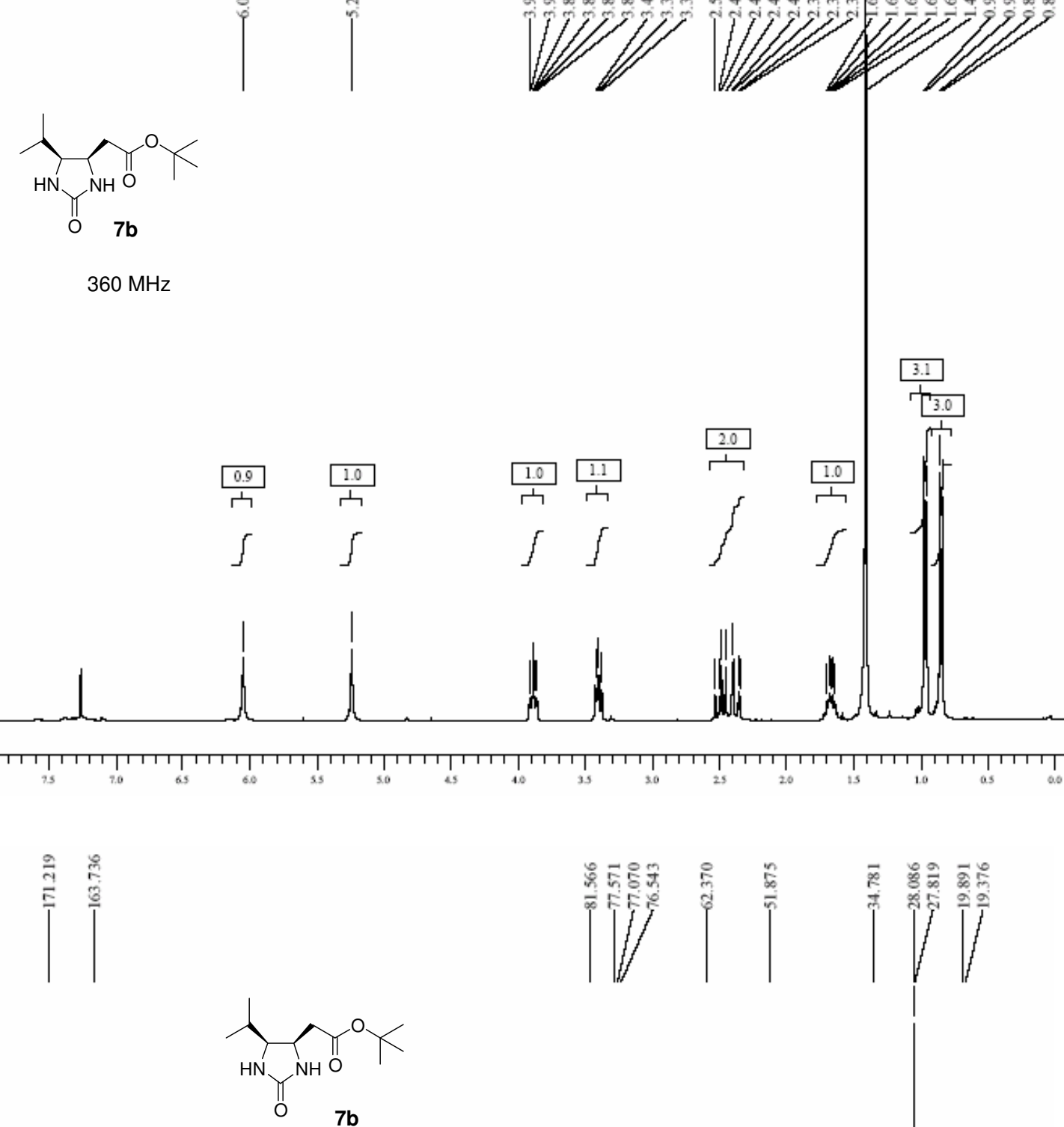

$62.5 \mathrm{MHz}$

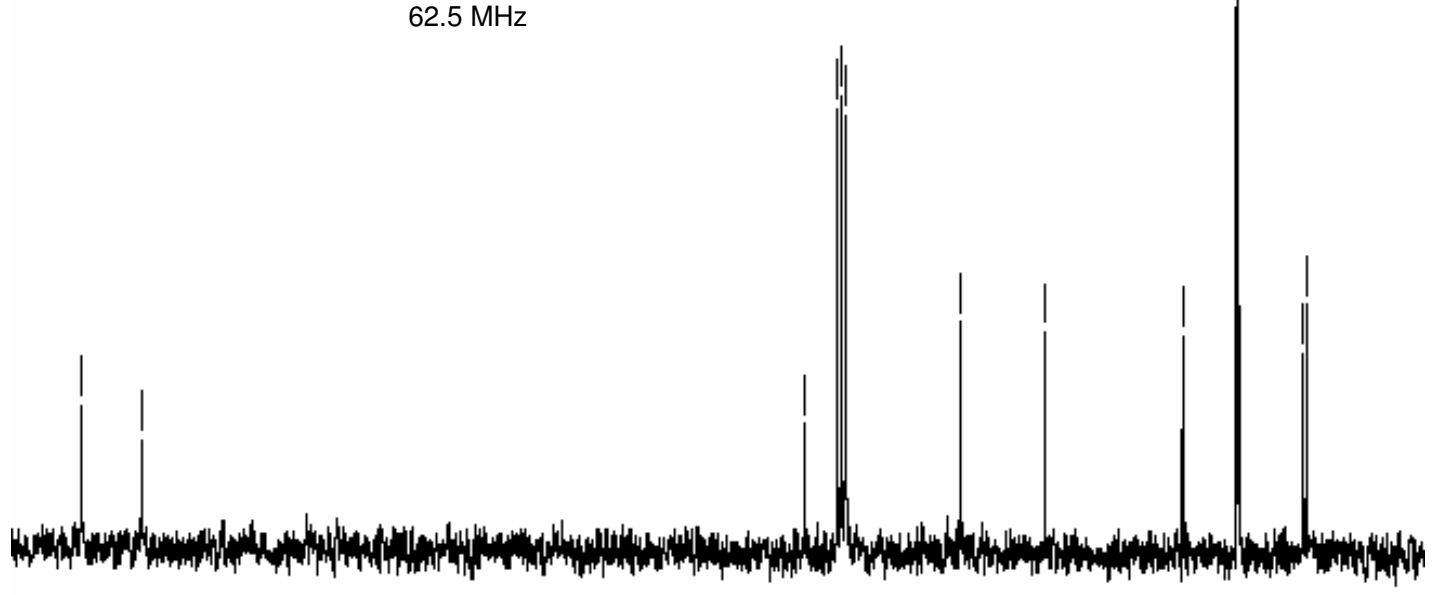




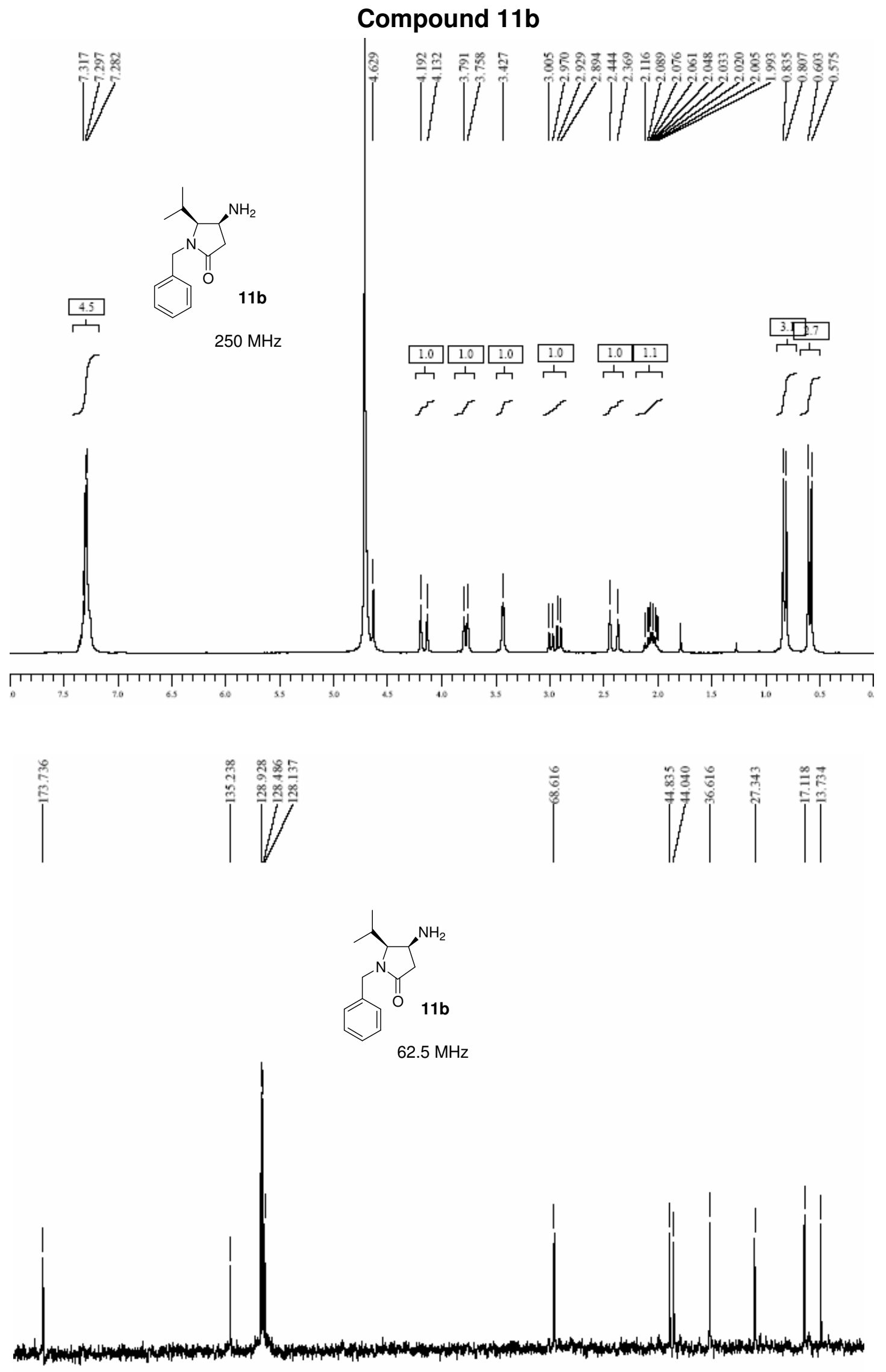




\section{Compound 10b}
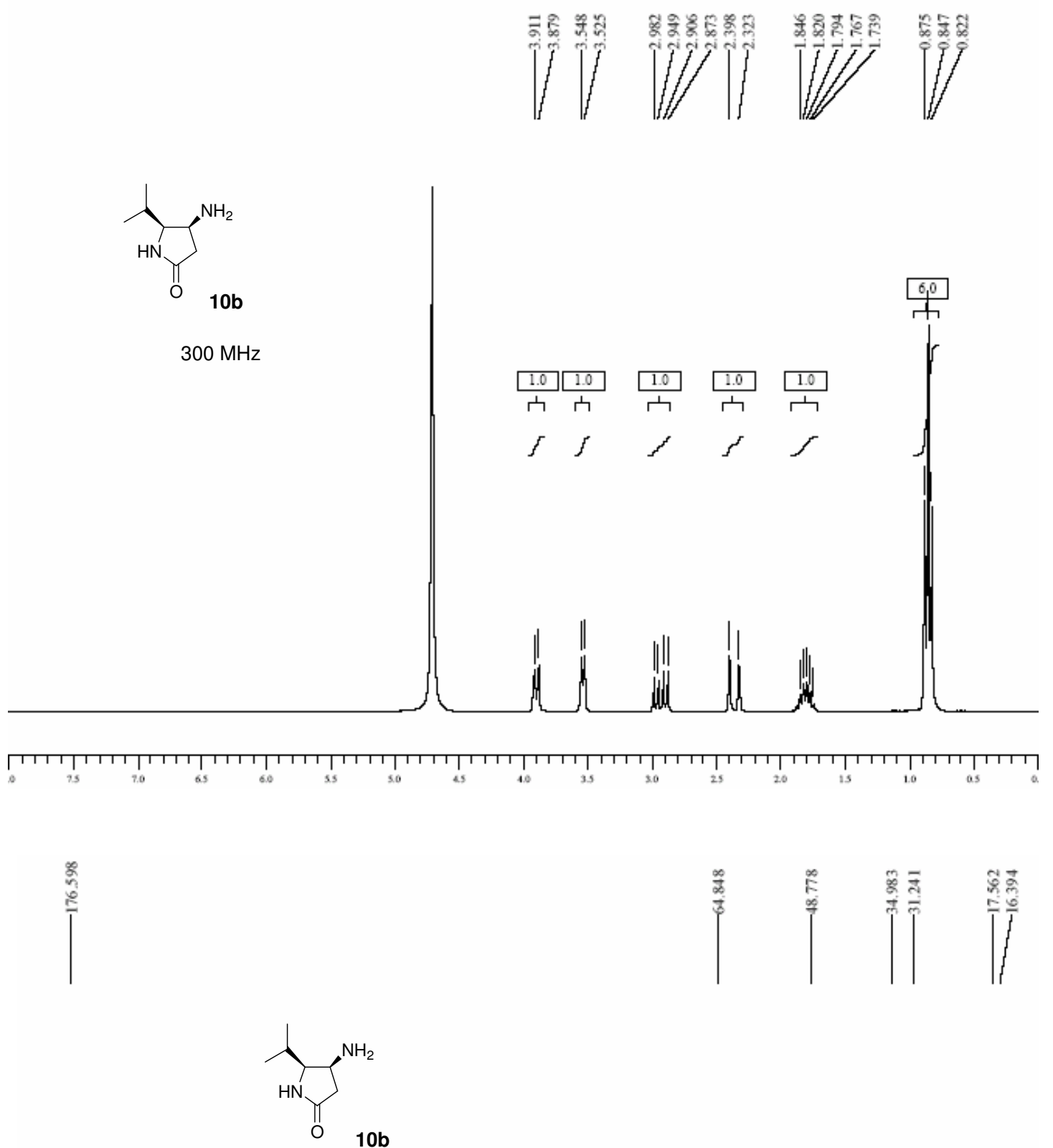

62.5 MHz

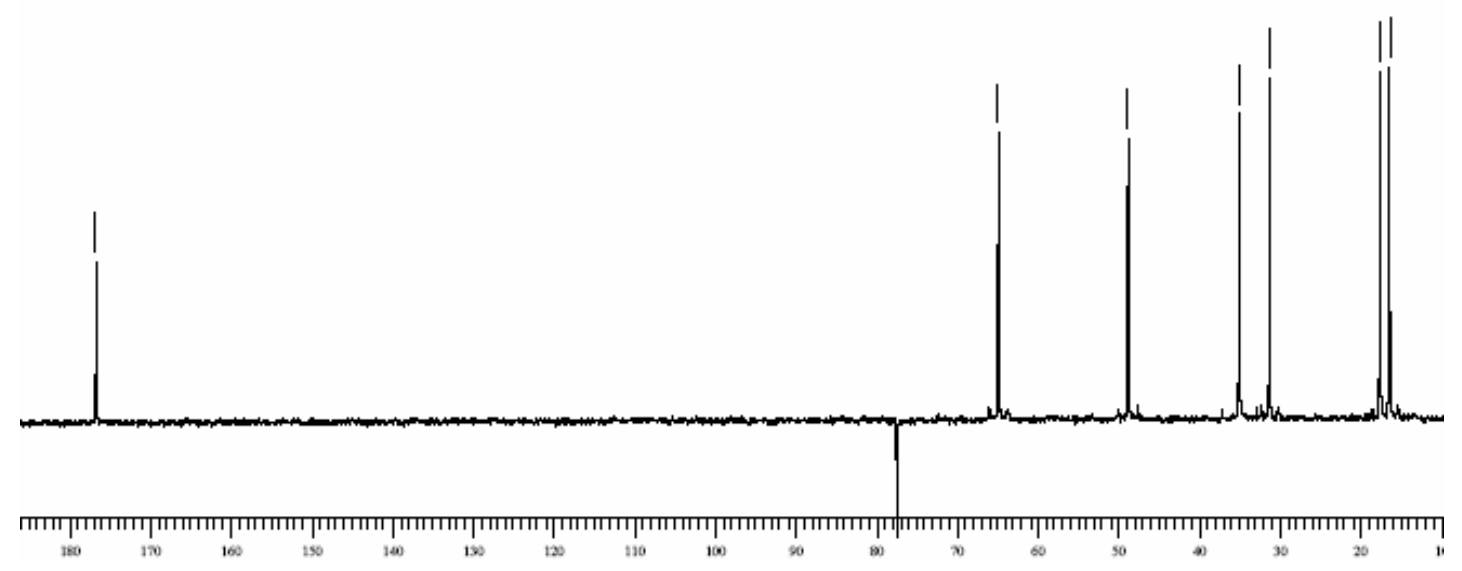

